\title{
El Cenozoico del alto río Teno, Cordillera Principal, Chile central: estratigrafía, plutonismo y su relación con estructuras profundas
}

\author{
José Piquer ${ }^{1}$, Juan Carlos Castelli ${ }^{2}$, Reynaldo Charrier ${ }^{3}$, Gonzalo Yáñez ${ }^{4}$ \\ 1 Exploraciones Mineras Andinas S.A., Apoquindo 4775, oficina 602, Santiago, Chile. \\ jpiquer@em.codelco.cl \\ 2 Geovectra S.A., Granada 2101, Santiago, Chile. \\ jccastelli@geovectra.cl \\ 3 Departamento de Geología, Universidad de Chile, Plaza Ercilla 803, Santiago, Chile. \\ rcharrie@cec.uchile.cl \\ 4 Gerencia Corporativa de Exploraciones, Huérfanos 1270, oficina 880, Santiago, Chile. \\ gyane003@codelco.cl
}

\begin{abstract}
RESUMEN. La evolución geológica cenozoica del sector central de la Cordillera Principal a $\sim 35^{\circ} \mathrm{S}$, se encuentra íntimamente relacionada con la evolución de estructuras profundas, las cuales habrían controlado, en distintas etapas de su historia, tanto la depositación de secuencias volcano-sedimentarias como el ascenso y emplazamiento de cuerpos intrusivos. Estudios estratigráficos en el entorno de estas estructuras, permiten confirmar la edad cenozoica de un conjunto de rocas piroclásticas y sedimentarias que subyacen concordantemente a lavas andesíticas de la Formación Abanico (asignada al Eoceno Tardío-Mioceno Temprano a Medio). Se determinó la existencia de cuatro fases intrusivas principales (diorita, granodiorita, pórfido riodacítico y pórfido dacítico, en ese orden de intrusión), cuyos productos afloran siguiendo una franja de orientación norte-sur. La granodiorita fue datada en 7,8 $\pm 0,4 \mathrm{Ma}$ (K-Ar en biotita). Pórfidos riodacíticos, considerados como facies marginales de la unidad anterior, se dataron en 7,9 $\pm 0,4 \mathrm{Ma}$ (K-Ar en fenocristales de plagioclasa). Se reconocieron dos estructuras de importancia regional: el Corrimiento El Fierro, y, más al oeste, se definió el Sistema de Fallas Infiernillo-Los Cipreses. En la caracterización de esta última estructura, se utilizó la modelación magnética de secciones como complemento a la información geológica. Se interpreta que el ascenso de las distintas fases intrusivas mencionadas fue controlado por el Sistema de Fallas Infiernillo-Los Cipreses. Este, al igual que el Corrimiento El Fierro, habría actuado como una falla normal de borde de cuenca durante el Eoceno Tardío-Mioceno Medio, controlando la depositación de productos volcánicos y sedimentarios de la Formación Abanico. Ambas fallas fueron reactivadas en modo inverso durante un importante episodio de contracción tectónica y de elevada presión de fluidos inducida por circulación de magmas, en el Mioceno Tardío, focalizando el ascenso de los intrusivos mencionados.
\end{abstract}

Palabras clave: Andes, Chile central, Estructuras profundas, Cenozoico, Cuenca Abanico-Farellones, Magnetometría.

\begin{abstract}
The Cenozoic of the upper Teno River, Cordillera Principal, Central Chile: stratigraphy, plutonism and their relation with deep structures. The Cenozoic geologic evolution of the central part of the Cordillera Principal at $\sim 35^{\circ} \mathrm{S}$, is intimately related to the geodynamic evolution of deep crustal structures, which during different stages controlled the deposition of volcanosedimentary sequences, and the ascent and emplacement of epizonal intrusions. Newly defined stratigraphy around these structures confirms the Cenozoic age of a group of pyroclastic and sedimentary rocks, which conformably underlie andesitic lavas of the Abanico Formation (assigned to the Late Eocene-Early to Middle Miocene). Intrusive rocks correspond to four main phases (from oldest to youngest: diorite, granodiorite, rhyo-dacitic and dacitic porphyry), which occurs in a North-South trending belt. The granodiorite was dated at 7.8 $\pm 0.4 \mathrm{Ma}$ (K-Ar in biotite). Rhyo-dacitic porphyries, considered as a marginal lithodeme of the granodiorite, yielded 7.9 $\pm 0.4 \mathrm{Ma}$ (K-Ar in plagioclase phenocrysts). Two main structures of regional importance were observed: the El Fierro thrust, and, towards the west, the Infiernillo-Los Cipreses Fault System. In the characterization of the latter, magnetic modeling of cross-sections were analyzed as a complement to the geologic information. The ascent of the different intrusive phases mentioned before, is interpreted as being controlled by the Infiernillo-Los Cipreses Fault System. This structure, as well as the El Fierro thrust, acted as a basin-margin normal fault during the Late Eocene-Middle Miocene, controlling the deposition of the Abanico Formation. These faults were reactivated as reverse faults during an episode of major tectonic contraction and magmatic-induced high fluid pressure in the Late Miocene, focusing the ascent of the intrusive bodies.
\end{abstract}




\section{Introducción}

Numerosos estudios desarrollados en los Andes de Chile central (33-36 $\left.{ }^{\circ} \mathrm{S}\right)$, durante las últimas dos décadas, han revolucionado el conocimiento acerca de su evolución tectónica y paleogeográfica durante el Cenozoico, aportando evidencias para la comprensión de un episodio extensional con desarrollo de una extensa cuenca volcano-tectónica (Cuenca de Abanico, Charrier et al., 2002, 2005; Godoy y Lara, 1994; Godoy et al., 1999) en la vertiente occidental de la Cordillera Principal. Los procesos geológicos que habrían condicionado la evolución de esta cuenca de intraarco estarían asociados a un progresivo adelgazamiento de la corteza, sucedida por un episodio de contracción tectónica que se inicia en el Mioceno Temprano (Charrier et al., 2002, 2005), el cual habría causado la inversión de la cuenca, la deformación de sus depósitos y la reactivación de las fallas normales asociadas al episodio de extensión, algunas de las cuales controlaron el emplazamiento de cuerpos intrusivos sintectónicos (Godoy, 1998).

Este artículo presenta los resultados de estudios recientes de geología estructural, estratigrafía, geocronología, susceptibilidad magnética y mapeo geológico a escala 1:25.000, desarrollados en la región oriental del valle del río Teno, en el sector comprendido entre el mencionado río y las lagunas del Teno y entre el río Infiernillo y el río Vergara (Fig. 1). Este sector se encontraba cubierto (en algunos casos parcialmente) por estudios de carácter regional (Klohn, 1960; González y Vergara, 1962; Davidson, 1971; Davidson y Vicente, 1973; Spichiguer, 1993) y su geología requería ser reinterpretada a la luz de los nuevos trabajos que han redefinido la estratigrafía, estructura y evolución de la Cordillera Principal más al norte, en el resto

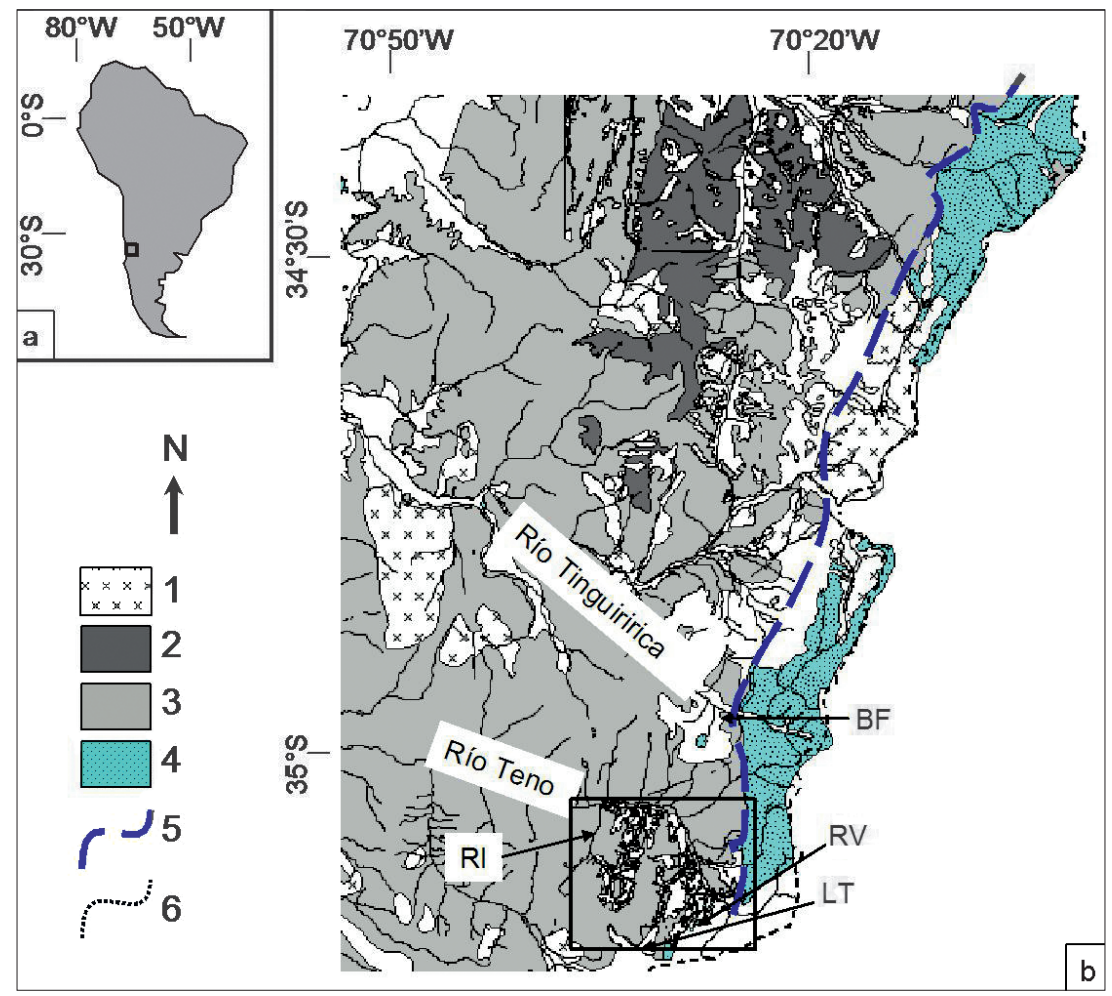

FIG. 1. a. Ubicación del área de estudio en América del Sur; b. Mapa geológico simplificado de la parte sur de Chile central, con el área de estudio enmarcada en negro. En blanco rocas volcánicas y sedimentos no consolidados del Cuaternario. 1. Intrusivos mio-pliocenos; 2. Formación Farellones (Mioceno Temprano a Tardío); 3. Formación Abanico (Eoceno Tardío-Mioceno Temprano a Medio); 4. Rocas sedimentarias y volcánicas mesozoicas; 5. Corrimiento El Fierro; 6. Límite internacional. Se indican algunas de las localidades geográficas mencionadas en el texto. RI: Río Infiernillo; RV: Río Vergara; LT: Lagunas del Teno; BF: Baños del Flaco. 
de Chile central. Los estudios que aquí se presentan permitieron aportar evidencias a favor de la noción de una cuenca extensional invertida a esta latitud, caracterizar las principales estructuras presentes y su relación con el magmatismo, precisar la cronología de algunos de los eventos involucrados en esta evolución e integrar los antecedentes obtenidos con aquellos disponibles de los demás estudios recientes desarrollados en la Cordillera Principal central.

\section{Marco Geológico}

Los depósitos cenozoicos prepliocenos de Chile central $\left(33^{\circ}-36^{\circ} \mathrm{S}\right)$, que constituyen el grueso de la Cordillera Principal en la región, son las formaciones Abanico, de edad Eoceno Tardío-Mioceno Temprano a Medio, y Farellones, del Mioceno Temprano a Tardío (Aguirre, 1960; Klohn, 1960; González y Vergara, 1962; Drake et al., 1982; Charrier et al., 1996, 2002; Fuentes et al., 2002). El traslape de edad entre ambas formaciones se debe al diacronismo del contacto, el cual en términos generales es más joven hacia el sur de la región considerada (Charrier et al., 2005). La Formación Abanico consiste en hasta $3.000 \mathrm{~m}$ de rocas volcánicas, en algunos sectores con afinidades toleíticas y en otros calcoalcalina (Hollings et al., 2005). Contiene intercalaciones piroclásticas, volcanoclásticas y subordinadamente sedimentarias, las cuales localmente se encuentran fuertemente plegadas. Además, incluye numerosas intrusiones subvolcánicas de la misma edad del volcanismo (Vergara et al., 2004), y presenta una paragénesis de minerales metamórficos de bajo grado bien desarrollada (Levi et al., 1989; Bevins et al., 2003; Fuentes et al., 2002; Fuentes, 2004). Los afloramientos de esta formación forman dos cinturones N-S separados por la Formación Farellones (Fig. 1). En su borde oriental, la Formación Abanico se encuentra, generalmente, en contacto por falla con las rocas mesozoicas (Falla El Diablo-Las Leñas-El Fierro, Fig. 1; Davidson, 1971; Davidson y Vicente, 1973; Godoy, 1991; Godoy y Lara, 1994; Charrier et al., 1994, 1996; Godoy et al., 1999; Fock et al., 2005). Esta(s) falla(s) corresponde(n) a fallas inversas de alto ángulo que presentan evidencias de haber sido originalmente fallas normales que fueron invertidas (Charrier et al., 1996, 2002, 2005). Estas estructuras habrían controlado la apertura de una cuenca volcano-tectónica extensional (Cuenca de Abanico o Cuenca de Coya-Machalí), en la que se depositaron rocas volcánicas y volcanoclásticas durante el Eoceno Tardío-Mioceno Medio, la cual habría sido invertida durante eventos compresivos del mio-plioceno (Godoy et al., 1999; Charrier et al., 2002, 2005). En algunas localidades se observa, además, que los depósitos de la Formación Abanico se disponen discordantemente sobre las unidades mesozoicas pertenecientes a las cuencas de trasarco de la Primera Etapa del Ciclo Andino, Jurásico y Cretácico Temprano (Charrier et al., 1996, 2002; Fock et al., 2006). De acuerdo al trabajo de Davidson (1971), en la zona de estudio las unidades mesozoicas presentes corresponden a las formaciones Nacientes del Teno (Bajociano Temprano-Oxfordiano Tardío), Río Damas (Kimmeridgiano) y Baños del Flaco (Titoniano-Neocomiano), además de afloramientos muy restringidos del Grupo Choiyoi (Permo-Triásico).

La Formación Farellones es una sucesión casi enteramente volcánica de carácter calcoalcalino, suavemente plegada, y que aflora aproximadamente entre $32^{\circ}$ y $35^{\circ} \mathrm{S}$ (Vergara et al., 1988). Alcanza un espesor de $2.400 \mathrm{~m}$ y consiste en lavas andesíticas a riolíticas, depósitos piroclásticos, volcanoclásticos, y escasas intercalaciones sedimentarias (Thiele, 1980; Charrier, 1981; Vergara et al., 1988). Su contacto con la subyacente Formación Abanico se presenta concordante y discordante según la zona de estudio considerada, en general dependiendo de la cercanía con estructuras que hayan producido plegamiento en la Formación Abanico, previo a la depositación de la Formación Farellones (Charrier et al., 2002). Como ha sido mencionado anteriormente, la edad del contacto es variable, en general disminuyendo hacia el sur (Charrier et al., 2005).

La actividad plutónica asociada con esta evolución se aloja principalmente en rocas de la Formación Abanico y es contemporánea con la depositación de la Formación Farellones. En general, los plutones se disponen formando alineaciones discontinuas de orientación aproximadamente paralela a la cadena Andina y de edad decreciente hacia el este (Aguirre, 1960; González y Vergara, 1962; Kurtz et al., 1997), algunos de los cuales están asociados a pórfidos 'supergigantes' de Cu-Mo, de edad Mioceno Tardío-Plioceno (Los Pelambres, Río Blanco-Los Bronces, El Teniente), desarrollados en zonas de alteración asociadas a 'stocks' multifásicos, brechas hidrotermales y diatremas, emplazados en rocas de las formaciones Abanico y/o Farellones (Serrano et al., 1996; Skewes et al., 2002; Maksaev et al., 2004). 


\section{Reinterpretación de la estratigrafía}

En afloramientos ubicados en la parte alta del valle del río Teno, primero asignados a la Formación Plan de los Yeuques (González y Vergara, 1962) y luego al miembro medio de la Formación Colimapu (Davidson, 1971), ambas de edad cretácica tardía, se realizó recientemente el hallazgo de fósiles de mamíferos que permiten afirmar sin lugar a dudas que, al menos, parte de las mencionadas rocas son de edad miocena temprana (Charrier et al., en prensa; Andre R. Wyss, comunicación verbal, 2009), pertenecientes probablemente a la Formación Abanico. Una situación similar se había producido anteriormente en el sector de Termas del Flaco (valle del río Tinguiririca) inmediatamente al norte (Charrier et al., 1990, 1996; Wyss et al., 1994).

Sobre la base de la continuidad estratigráfica observada en la zona de trabajo (Fig. 2), y partiendo del conocimiento de la edad terciaria del nivel piroclástico donde se realizó el hallazgo de restos de mamíferos fósiles, se puede concluir que todas las rocas asignadas por Davidson (1971) a la Formación Colimapu, facies volcánica, son en realidad de esa edad. Esto corrobora la interpretación dada por Spichiguer (1993), quien había asignado a la Formación Abanico todas las rocas estratificadas del área de estudio al oeste del Corrimiento El Fierro. En el presente artículo se agrupan estas rocas principalmente piroclásticas como un miembro de la Formación Abanico, al cual se hará referencia como miembro oriental, por su ubicación geográfica en la zona de estudio (Fig. 2). Las rocas andesíticas suprayacentes serán denominadas informalmente en el presente trabajo como miembro occidental. Estas fueron asignadas por Davidson (1971) a la Formación Abanico, y se componen de andesitas porfíricas de piroxeno y brechas volcánicas andesíticas. Si bien por su posición sobre rocas piroclásticas del Mioceno Temprano estas rocas podrían corresponder eventualmente a la base de la Formación Farellones, por su contacto estratigráfico concordante sobre las rocas subyacentes, y por encontrarse plegadas solidariamente con las mismas, en este trabajo se asigna esta secuencia al techo de la Formación Abanico.

\subsection{Miembro oriental}

En la parte sur del área de estudio, aflora en los cordones montañosos que se encuentran entre los ríos Malo por el oeste y Vergara por el este. Más al norte, aflora inmediatamente al este del valle del río Teno. La columna estratigráfica tipo se muestra en la figura 3. En ella se diferencia entre las unidades presentes en la parte sur del área de estudio (columna A, subdividida en las unidades A1, A2, A3 y A4) de las presentes en la parte norte (columna $\mathrm{B}$, unidades B1 y B2). Se indica también la equivalencia entre las unidades de ambas columnas. A continuación se describe la columna A, la cual aflora entre los ríos Malo y Vergara:

\subsubsection{Unidad $A 1$}

Niveles de 1-2 $\mathrm{m}$ de espesor de conglomerados polimícticos con matriz de arenisca rojiza, clastos subredondeados de andesita y, en menor medida, de toba, de tamaño 3 a $7 \mathrm{~cm}$. La potencia estimada de esta unidad es de $70 \mathrm{~m}$. Se interpretan como depósitos fluviales moderadamente trabajados.

\subsubsection{Unidad A2. Alternancias de:}

- Lavas andesíticas porfíricas (fenocristales de plagioclasa en masa fundamental afanítica gris) o afaníticas en capas de 2-6 m de espesor.

- Areniscas epiclásticas grises de grano medio y grueso, bien estratificadas, en bancos de 10-20 $\mathrm{cm}$ de espesor.

- Lutitas con laminación milimétrica en bancos de $10 \mathrm{~cm}$ de espesor, interpretadas como depositadas en un ambiente lacustre.

- Brechas sedimentarias matriz soportadas con clastos de andesita y toba, angulosos y mal seleccionados, de 2 a $7 \mathrm{~cm}$, que forman niveles de 1 a $5 \mathrm{~m}$ de potencia, interpretados como producto de eventos de remoción en masa tipo flujos de detritos. $250 \mathrm{~m}$.

El espesor total estimado de esta unidad es de

\subsubsection{Unidad A3}

Secuencia ininterrumpida de rocas piroclásticas. Se observan principalmente tobas de lapilli líticas y tobas de ceniza cristalinas, de color verdoso debido a la presencia de celadonita. Los piroclastos son líticos de andesita, plagioclasa, cuarzo con embahiamientos y en algunos casos pómez elongadas (estos últimos correspondientes a niveles de tobas soldadas con textura eutaxítica). La matriz es de ceniza y esquirlas. Algunos niveles contienen fragmentos de madera carbonizada. La secuencia se interpreta como producto de sucesivas oleadas piroclásticas intercaladas 


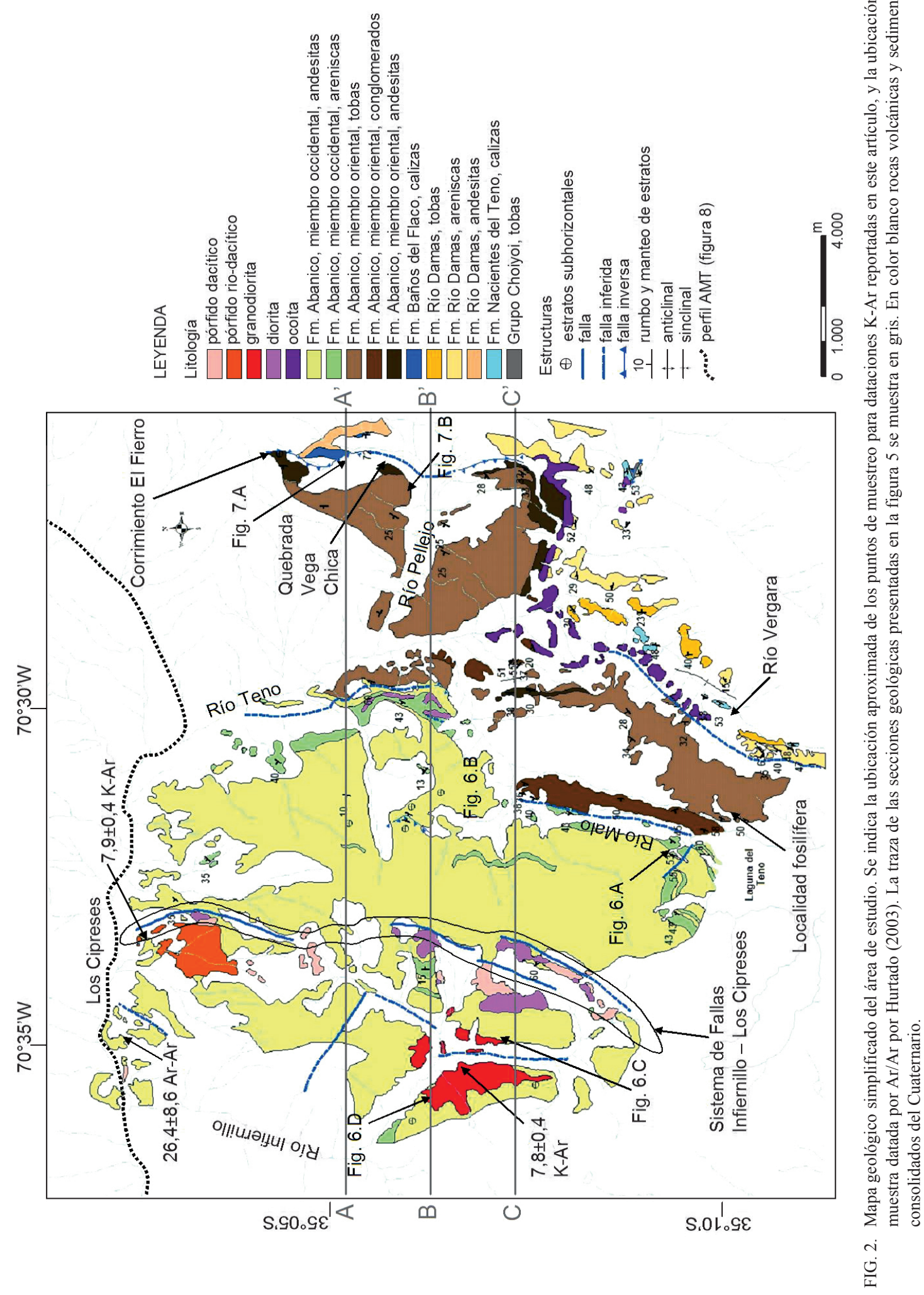


con flujos piroclásticos pumíceos (ignimbritas). Los estratos tienen desde 1 hasta $15 \mathrm{~m}$ de potencia. El espesor total estimado de la unidad varía entre 800 y $1.100 \mathrm{~m}$. A la parte superior de esta unidad pertenece el nivel piroclástico donde se realizó el hallazgo de restos fósiles de mamíferos cenozoicos (Charrier et al., en prensa; Andre R. Wyss, comunicación verbal, 2009).

\subsubsection{Unidad $A 4$}

Continúa la secuencia piroclástica pero se observan además intercalaciones de:

- Brechas sedimentarias matriz soportadas con clastos angulosos de andesita y toba de tamaño variable entre 2 y $15 \mathrm{~cm}$, en niveles de 1 a $2 \mathrm{~m}$ de espesor, interpretados como depósitos de flujos de detritos.

- Lavas andesíticas, en sectores autobrechizados, en bancos de 3 a $6 \mathrm{~m}$ de espesor.

- Areniscas epiclásticas de grano grueso, de color gris, en niveles de 20 a $50 \mathrm{~cm}$ de espesor.

- Calcilutitas y niveles limosos, en ocasiones con laminación milimétrica interna, en bancos de 15 a $50 \mathrm{~cm}$ de espesor, interpretados como asociados a ambiente lacustre.

- Conglomerados epiclásticos de grano medio, grueso y muy grueso, observándose tanto niveles clastosoportados como matriz soportados. Los clastos son de andesita y toba bien redondeados de tamaño entre 2 y $10 \mathrm{~cm}$, alcanzando en un nivel muy grueso hasta $30 \mathrm{~cm}$. La matriz es de arenisca epiclástica. La potencia de los estratos en general varía entre 1 y $5 \mathrm{~m}$, alcanzando hasta $15 \mathrm{~m}$ en el caso de los niveles muy gruesos. Se interpretan como asociados a depósitos fluviales de alta energía, producto de la erosión de los centros volcánicos de la época.

- Los niveles tobáceos presentan frecuentemente fragmentos de madera carbonizada. También se observaron restos vegetales en una capa de limo. El espesor estimado de esta unidad es de $550 \mathrm{~m}$.

Aproximadamente $5 \mathrm{~km}$ más al norte, entre los ríos Pellejo y Nacimiento y en los alrededores de Pichuante, se observó, de base a techo (columna B):

\subsubsection{Unidad B1}

Equivalente a la unidad A2 de la columna A. E1 espesor estimado de esta unidad es de $200 \mathrm{~m}$. Se compone de intercalaciones de:
- Niveles de 3 a $6 \mathrm{~m}$ de potencia de lavas andesíticas porfíricas, con fenocristales de plagioclasa de 1-2 mm en una masa fundamental afanítica gris oscuro.

- Conglomerados epiclásticos finos y medios, polimícticos, en general bien seleccionados. Los clastos son de andesitas porfíricas, lavas afaníticas y tobas. Matriz de arcilla. Estratos de $50 \mathrm{~cm}$ a $1 \mathrm{~m}$ de espesor. Se interpretan como depósitos de tipo fluvial moderadamente trabajados, provenientes de la erosión de rocas volcánicas.

- Niveles de 20 a $30 \mathrm{~cm}$ de espesor compuestos por limo y arenisca gris de grano fino, interpretadas como depositadas en un ambiente fluvial de baja energía a lacustre.

\subsubsection{Unidad B2}

Equivalente a la unidad A3 de la columna A. Es una potente secuencia piroclástica, donde las litologías predominantes son toba de ceniza cristalina y toba de lapilli lítica con fragmentos andesíticos de diversos tamaños, alcanzando hasta $10 \mathrm{~cm}$ de diámetro en algunas ocasiones. La estratificación es gruesa, con estratos de espesores variables entre 5 y $15 \mathrm{~m}$. Al igual que en la unidad A3, aparecen niveles que contienen fragmentos de madera carbonizada. Se interpreta como una sucesión de flujos y oleadas piroclásticas. El espesor total estimado de esta unidad es de $1.700 \mathrm{~m}$.

\subsubsection{Síntesis del miembro oriental}

El espesor total estimado del miembro oriental es de aproximadamente $1.900 \mathrm{~m}$. Se observa que las dos columnas tipo son fácilmente correlacionables, siendo la unidad A2 equivalente a la B1 y la unidad A3 equivalente a la B2. Faltan en la columna B las intercalaciones sedimentarias finas observadas hacia el techo de la columna A (unidad A4).

$\mathrm{Al}$ este, en la parte norte del área de estudio, el miembro oriental se encuentra en contacto por falla (Corrimiento El Fierro) con las unidades mesozoicas (formaciones Nacientes del Teno, Río Damas y Baños del Flaco); en la parte sur, el contacto se encuentra ocupado por un pórfido andesítico grueso (ocoíta en figura 2), sin que se hayan encontrado evidencias concluyentes acerca de si éste se emplazó a lo largo de una discordancia o en un plano de falla. Al oeste, subyace concordantemente a lavas y sedimentitas del miembro occidental de la Formación Abanico. 
La fauna fósil de edad miocena temprana encontrada en el miembro oriental se ubica en la parte superior de la columna estratigráfica (hacia el techo de la unidad A3=B2, Fig. 3; Charrier et al., en prensa; Andre R. Wyss, comunicación verbal, 2009). Las faunas Tinguiririca y Tapado, documentadas en el sector de Baños del Flaco (Wyss et al., 1994), también contenidas en niveles piroclásticos de la Formación Abanico, tienen una edad en el rango Eoceno Tardío-Oligoceno Temprano. De lo anterior, las rocas del miembro oriental en el área de estudio se pueden acotar preliminarmente al rango Eoceno Tardío-Mioceno Temprano.

El miembro oriental evidencia dos episodios geológicos con condiciones de sedimentación y carácter del volcanismo marcadamente distintos.
Primero, se depositaron en la zona lavas andesíticas alternadas con abundantes depósitos fluviales (conglomerados finos, medios y gruesos) y lacustre (limo y areniscas finas; unidades A1 y A2=B1 en figura 3).

Luego se produce una transición hacia un importante episodio volcánico de carácter explosivo (unidades A3=B2), con potentes depósitos piroclásticos, que presentan intercalaciones sedimentarias de alta energía, como depósitos de flujos de detritos y conglomerados gruesos. Hacia el final de este episodio volcánico, en la parte sur del área de estudio, se producen interrupciones en la depositación de las volcanitas que permiten la acumulación de sedimentos lacustres y fluviales (unidad A4). Estos indican una mayor distalidad respecto de los centros
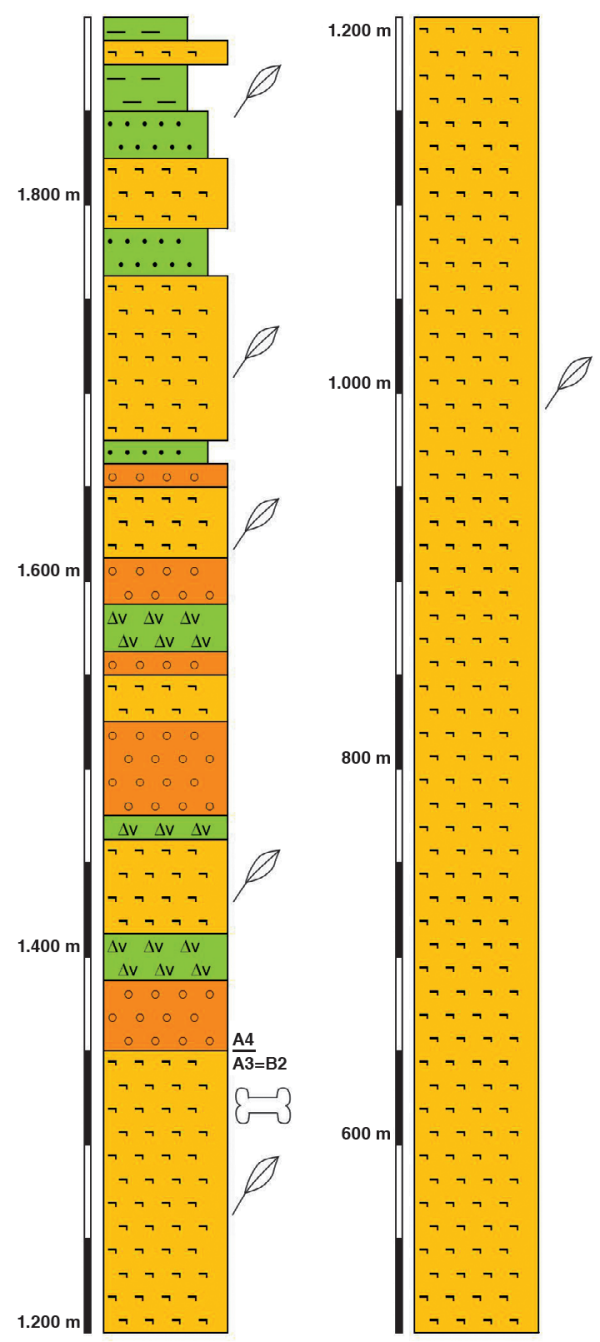
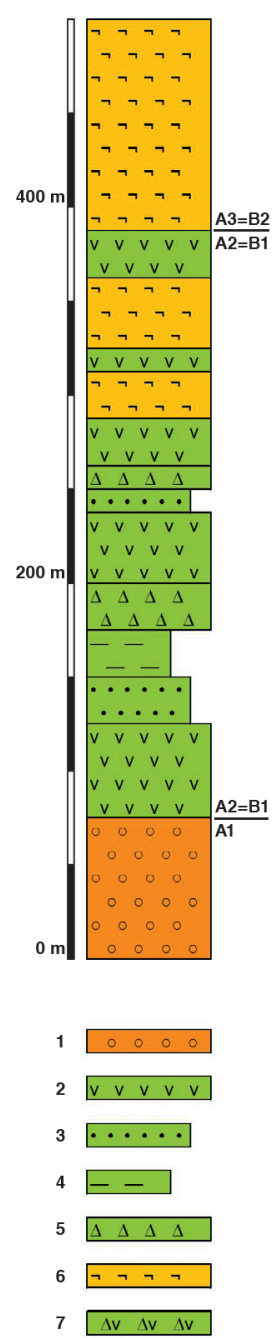

FIG. 3. Columna estratigráfica generalizada del miembro oriental. Se indican los límites entre las unidades descritas en el texto, y los niveles portadores de flora y/o fauna fósil. 1. conglomerados polimícticos con clastos de andesita y toba; 2. lavas andesíticas; 3. litarenitas; 4. lutitas laminadas y limo; 5. depósito de flujos de detritos; 6 . tobas de lapilli líticas y tobas de ceniza cristalinas; 7. brechas volcánicas andesíticas. 
volcánicos de la época, en comparación con la parte norte, donde la secuencia piroclástica no presenta intercalaciones sedimentarias.

\subsection{Miembro occidental}

Sus afloramientos cubren la mayor parte del sector central y oeste del área de estudio, inmediatamente al oeste de los valles de los ríos Teno y Malo. La columna estratigráfica tipo se muestra en la figura 4 (ver figura 5). Esta fue levantada en la ladera occidental de los ríos mencionados. Se puede separar en las siguientes unidades:
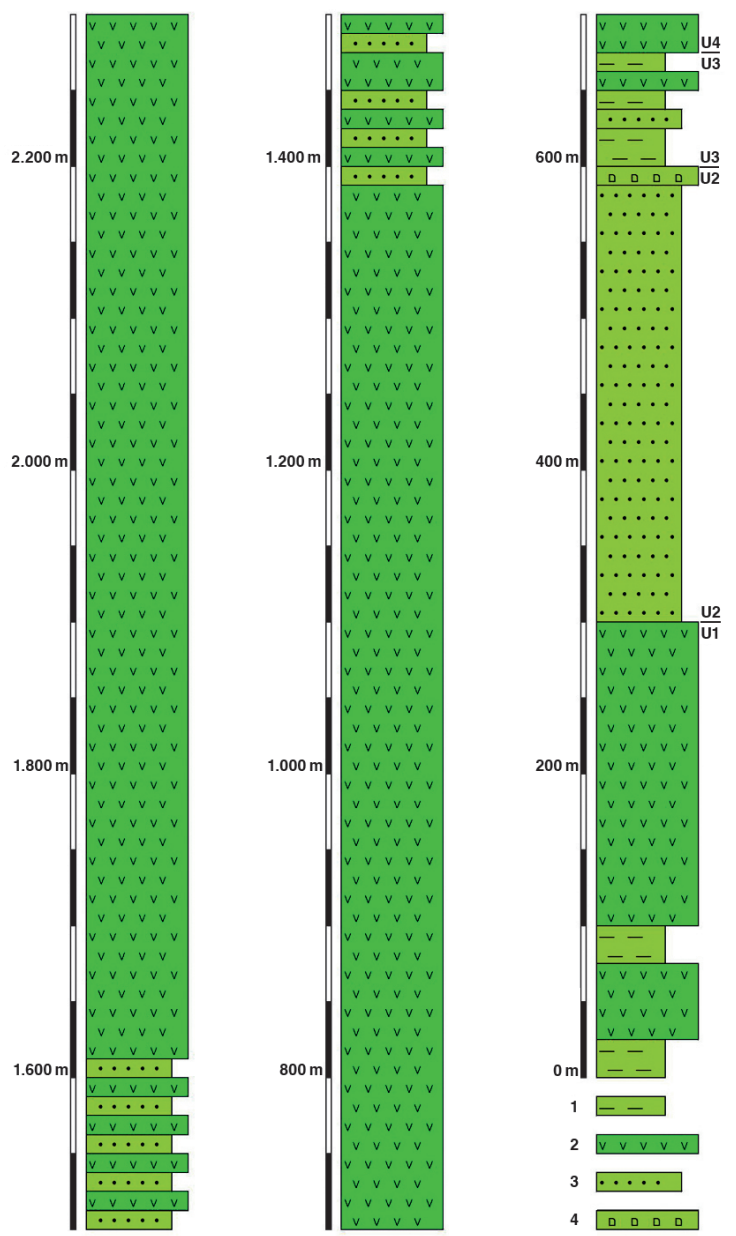

FIG. 4. Columna estratigráfica generalizada del miembro occidental. Se indican los límites entre las unidades descritas en el texto. 1. lutitas laminadas y limo; 2 . coladas de lava andesíticas; 3. litarenitas, wackas líticas y conglomerados epiclásticos finos; 4. depósito de flujo de detritos asociado a 'slumping'.

\subsubsection{Unidad 1}

Niveles de lavas andesíticas porfíricas, color gris, con fenocristales de plagioclasa de $2 \mathrm{~mm}$, que forman coladas de 2 a $12 \mathrm{~m}$ de potencia. En algunos sectores se encuentran despegados de las tobas del miembro oriental mediante una falla inversa de bajo ángulo. Espesor estimado $300 \mathrm{~m}$. Ocasionalmente esta unidad no está presente, encontrándose a la unidad 2 directamente en contacto concordante sobre el miembro oriental.

\subsubsection{Unidad 2}

Wackas líticas y wackas feldespáticas de grano medio y grueso, y conglomerados epiclásticos polimícticos de grano fino. Forman niveles bien estratificados en bancos de $30 \mathrm{cms}$ a $1 \mathrm{~m}$ de espesor, de color rojizo debido a la presencia de óxidos de hierro (Fig. 6A). Los clastos son fragmentos de andesita y de cristales de plagioclasa, moderadamente redondeados. La matriz es de arcilla, y se encuentra fuertemente reemplazada por calcita y hematita. En ocasiones se observa estratificación cruzada. Se interpretan como depósitos de energía moderada en ambiente fluvial, provenientes directamente de la erosión de centros volcánicos andesíticos. Aparecen algunas fallas internas menores (despegues con desplazamientos del orden de decenas de centímetros). Cerca del techo de esta unidad se observa, en las inmediaciones del desagüe de las Lagunas del Teno, un nivel de arenisca fuertemente deformado, mientras las capas supra y subyacentes, compuestas por una secuencia de lutitas, limo y areniscas, no se encuentran deformadas (ver figura 6A). Esto había sido considerado por autores anteriores (González y Vergara, 1962) como un nivel de despegue. Sin embargo, más abajo, en el valle del río Malo, se observa el mismo nivel estratigráfico pero desagregado en grandes fragmentos angulosos de arenisca con deformación interna (olistolitos) en una matriz arcillosa oscura. Esto permite interpretar que esta deformación se asocia a un evento de 'slumping', en ambiente lacustre, que afectó a sedimentos finos semiconsolidados, los que fueron desagregados en olistolitos en los sectores más afectados. El espesor estimado de la unidad 2 es variable entre 250 y $400 \mathrm{~m}$ (ver figura 6B).

\subsubsection{Unidad 3}

Estratos de 15 a $20 \mathrm{~cm}$ de espesor compuestos por: 
- Lutitas y calcilutitas grises con laminación interna milimétrica, compuestas por fragmentos de cuarzo y plagioclasa. Se interpretan como depósitos de baja energía en ambiente lacustre.

- Wackas y arenitas líticas finas a medias, de color gris, con clastos de andesita y fragmentos de plagioclasa.

Esta unidad es de carácter lenticular; en algunos sectores no está presente mientras que en otros alcanza hasta $100 \mathrm{~m}$ de espesor estimado.

\subsubsection{Unidad 4}

Compuesta por lavas andesíticas porfíricas con fenocristales de plagioclasa (1 a $3 \mathrm{~mm}$ ) y piroxeno $(0,5$ a $2 \mathrm{~mm})$ en una masa fundamental afanítica, gris, intercaladas con lavas afaníticas grises. En sectores los flujos aparecen autobrechizados. Los estratos tienen de 3 a $10 \mathrm{~m}$ de espesor. Se observan intercalaciones sedimentarias finas de 1 a 1,5 m de espesor, lenticulares, compuestas por wackas líticas gruesas y conglomerados finos epiclásticos de color rojizo. Los clastos son de andesita y ocasionalmente se observan fragmentos de cristales de plagioclasa. La matriz es de arcilla y aparece fuertemente reemplazada por calcita y hematita. En su litología y ambiente depositacional estas intercalaciones son idénticas a la unidad 2. El espesor total de la unidad 4 no puede ser determinado debido a que su techo no se observa en el área de estudio, pero su espesor mínimo estimado es de $1.500 \mathrm{~m}$.

$\mathrm{O}$

Sección A-A'

E

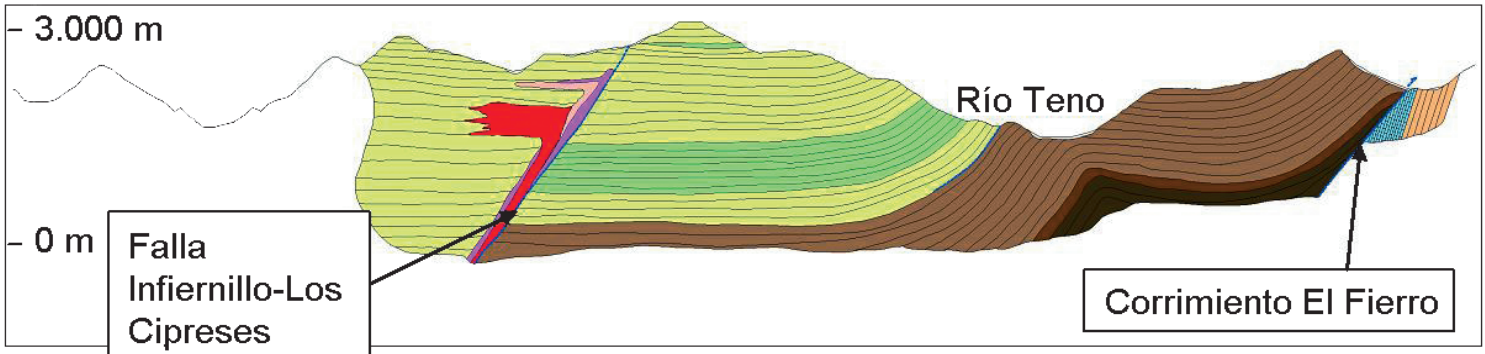

Sección B-B'

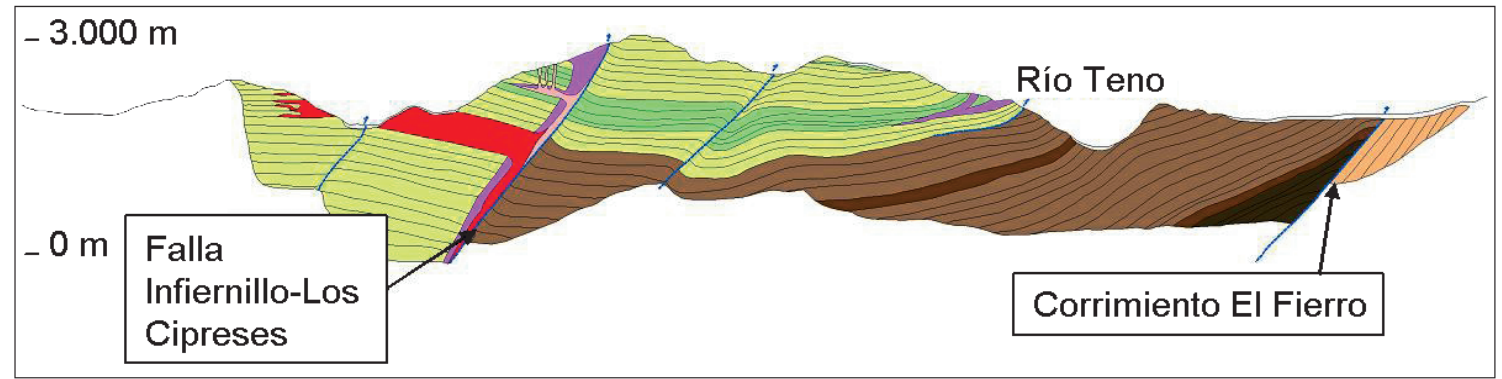

Sección C-C'

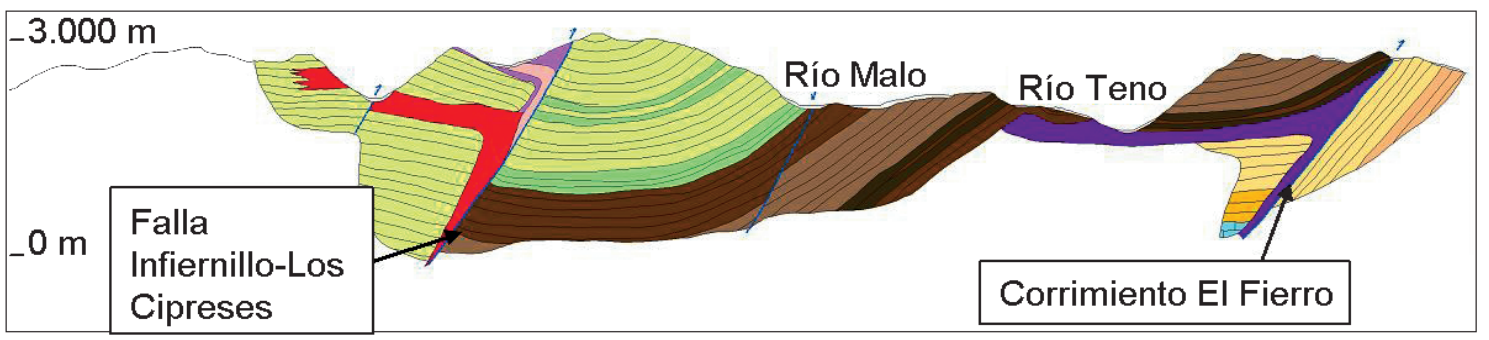

FIG. 5. Secciones geológicas representativas del área de estudio. Se indica la ubicación de las fallas principales. La leyenda es la misma que la presentada en la figura 2. 


\subsubsection{Síntesis del miembro occidental}

El espesor total mínimo de la columna descrita para el miembro occidental se estima en $2.300 \mathrm{~m}$.

De acuerdo a la columna estratigráfica (Fig. 4), se infiere un paso progresivo desde una posición proximal respecto a los centros volcánicos de la época, con depositación de lavas andesíticas (unidad 1), hacia un ciclo de depositación de litarenitas y conglomerados finos epiclásticos fluviales, evidencia de un cese temporal de la actividad volcánica en la zona (unidad 2, 'areniscas rojas de Pichuante', antiguamente consideradas típicas de la Formación Colimapu). Luego aparecen en algunos sectores sedimentos de carácter lacustre, marcadamente lenticulares (unidad 3). Posteriormente se observan nuevas coladas andesíticas intercaladas en los sedimentos, mostrando un resurgimiento de la actividad volcánica en el área de estudio, dando lugar finalmente a un importante episodio volcánico con depositación de flujos de lava andesíticos (unidad 4), con escasas intercalaciones sedimentarias fluviales (conglomerados finos y areniscas gruesas), también de carácter lenticular.

En conclusión, existe un cambio en el carácter del volcanismo respecto a lo observado en el miembro oriental, desapareciendo los depósitos de flujos piroclásticos y encontrándose solo coladas andesíticas, sedimentos volcanoclásticos y depósitos lacustres.

La columna estratigráfica descrita anteriormente, fue levantada en el bloque oriental del Sistema de Fallas Infiernillo-Los Cipreses (descrito más adelante, ver Fig. 2). Al oeste del mismo, continúa la sucesión de flujos de lava andesíticos de la unidad 4 del miembro occidental, pero su potencia se hace considerablemente mayor (Fig. 5). En la parte más baja de esta secuencia, en niveles volcánicos ubicados en el extremo NO del área abarcada en el presente estudio, Hurtado (2003) reportó una edad Ar/Ar de 26,4 $\pm 8,6 \mathrm{Ma}$ (Oligoceno Tardío, Ar/ $\mathrm{Ar}$ en plagioclasa, ver Fig. 2). Esto indica que la depositación de los flujos de lava andesíticos del miembro occidental, se inició considerablemente antes al oeste del Sistema de Fallas Infiernillo-Los Cipreses que al este del mismo, donde las coladas se apoyan sobre rocas piroclásticas y sedimentarias portadoras de fauna fósil del Mioceno Temprano. Lo anterior implica que al menos parte de la depositación de las rocas piroclásticas del miembro oriental, al este de la estructura mencionada, ocurrió en forma simultánea con la emisión de flujos de lava andesí- ticos al oeste. El espesor mínimo estimado para la secuencia andesítica al oeste del Sistema de Fallas Infiernillo-Los Cipreses es de $2.500 \mathrm{~m}$ (estimado de mapa 1:25.000, secciones geológicas y modelación magnética, Figs. 2, 5 y 11).

La edad mínima del miembro occidental, por su parte, está dada por cuerpos intrusivos que lo cortan, datados en 7,8 $\pm 0,4$ y 7,9 $90,4 \mathrm{Ma}$ (Mioceno Tardío, $\mathrm{K}-\mathrm{Ar}$, este trabajo, ver capítulo siguiente).

\section{Rocas Intrusivas}

Los cuerpos intrusivos principales presentes en la zona de estudio forman una franja de orientación aproximada N-S (Fig. 2), entre las nacientes del río Infiernillo y el sector de Los Cipreses. Se diferenciaron dioritas de hornblenda, granodioritas de hornblenda y biotita ('granito de biotita' de González y Vergara, 1962), pórfidos riodacíticos de hornblenda y biotita ('Batolito Los Cipreses' de González y Vergara, 1962; 'Intrusivo del Estero Santa Rita' de Davidson, 1971), y pórfidos dacíticos de biotita, con ese orden de intrusión. La caja de este complejo intrusivo es el miembro occidental de la Formación Abanico.

Dioritas y pórfidos dacíticos presentan contactos discordantes con sus rocas de caja, y forman diques y 'stocks' elongados siguiendo la mencionada franja N-S (Fig. 2). Granodioritas y pórfidos riodacíticos, por su parte, muestran contactos tajantes, discordantes y subverticales inclinados al oeste a lo largo de la misma franja, la cual constituye su límite oriental (Figs. 2 y 5). En la zona de contacto se observan además evidencias de fallamiento, que afectan tanto a los cuerpos intrusivos como a su roca de caja (Sistema de Fallas Infiernillo-Los Cipreses, descrita en capítulo siguiente). Hacia el oeste, en cambio, aparecen en contacto subhorizontal y concordante con la estratificación de la Formación Abanico (Figs. 5 y 6C), formando cuerpos filonianos de unos $500 \mathrm{~m}$ de potencia, indicando que su emplazamiento se produjo en espacios dilatacionales generados entre distintos niveles de la mencionada unidad. En su borde occidental, los cuerpos intrusivos terminan en forma de filones que se acuñan hacia el oeste (Fig. 6D).

Para el presente trabajo se realizaron dos dataciones radiométricas $\mathrm{K}-\mathrm{Ar}$, efectuadas por el laboratorio de geocronología de SERNAGEOMIN (ver datos analíticos en tabla 1). En la granodiorita, se obtuvo una edad de 7,8 $\pm 0,4( \pm 2 \sigma)$ Ma (Mioceno Tardío), 

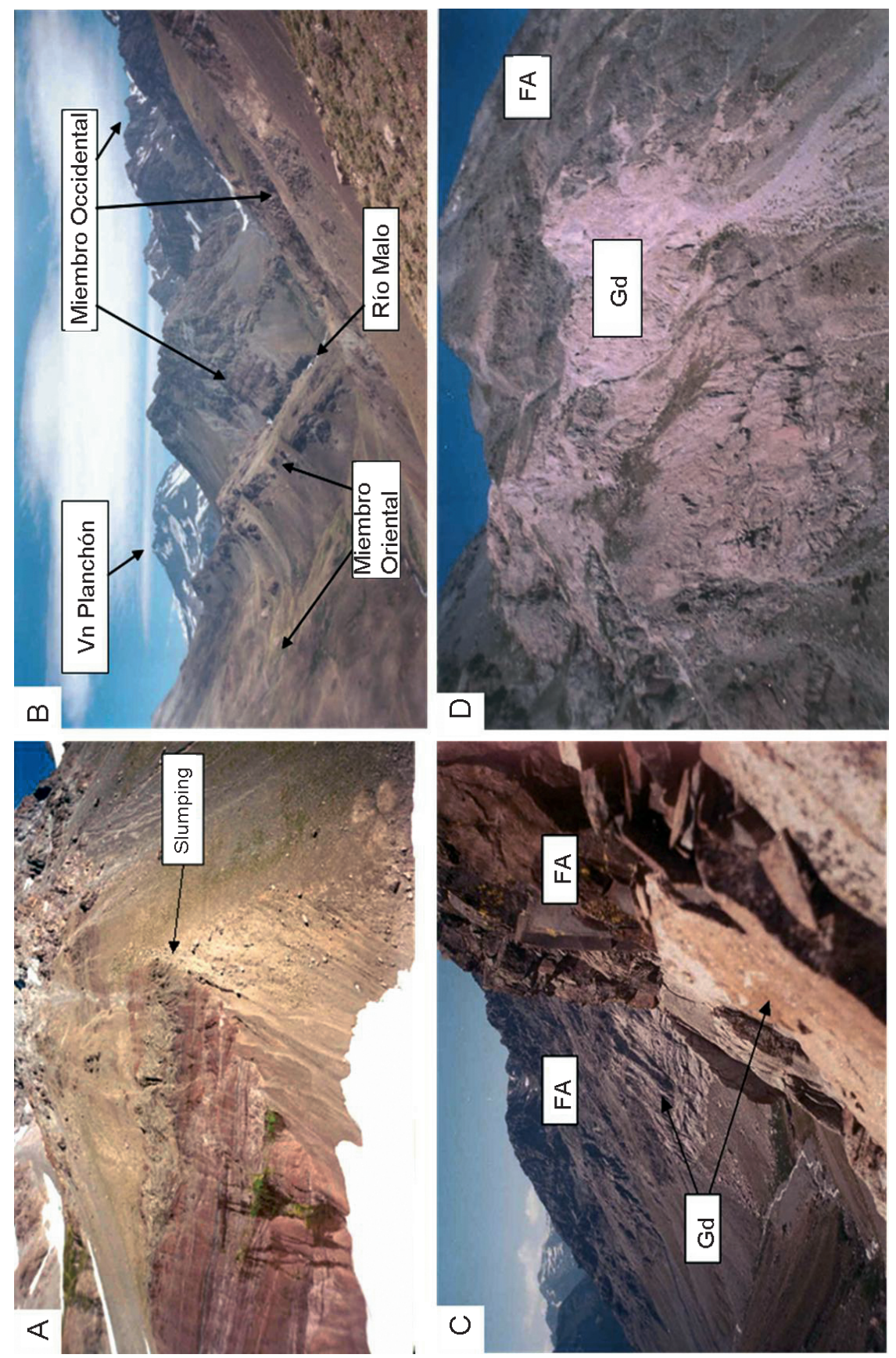

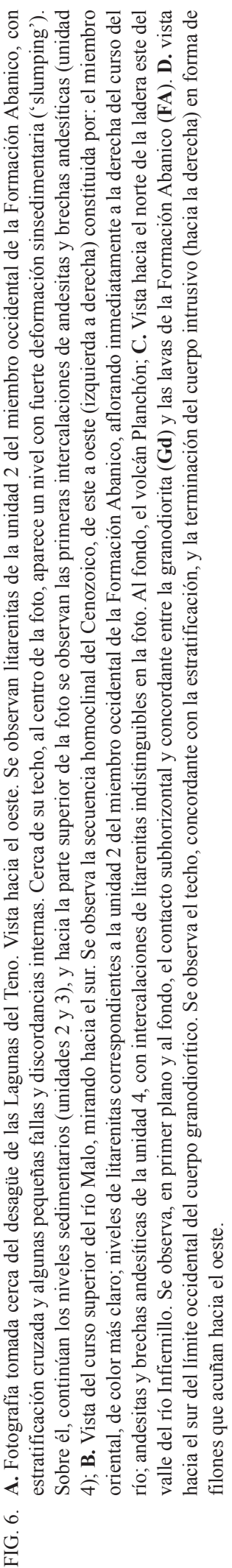


TABLA 1. DATOS ANALÍTICOS DE DATACIONES K-Ar EN INTRUSIVOS DE INFIERNILLO-LOS CIPRESES.

\begin{tabular}{|c|c|c|c|c|c|c|c|c|}
\hline $\mathbf{N}^{\circ}$ Muestra & Coordenadas UTM & Litología & Material & $\% \mathrm{~K}$ & $\begin{array}{c}\text { Ar Rad } \\
\text { nl/g }\end{array}$ & $\begin{array}{l}\text { \%Ar. } \\
\text { Atm }\end{array}$ & $\begin{array}{c}\text { Edad } \\
\text { Ma }\end{array}$ & $\begin{array}{c}\text { Error } \\
2 \sigma\end{array}$ \\
\hline 85138 & $6.113 .861 \mathrm{~N} / 354.428 \mathrm{E}$ & granodiorita & biotita & 6,953 & 2,103 & 53 & 7,8 & 0,4 \\
\hline 85206 & $6.120 .619 \mathrm{~N} / 357.768 \mathrm{E}$ & $\begin{array}{l}\text { pórfido } \\
\text { riodacítico }\end{array}$ & plagioclasa & 2,695 & 0,834 & 52 & 7,9 & 0,4 \\
\hline
\end{tabular}

en cristales de biotita. En el pórfido riodacítico, por su parte, se obtuvo un resultado de $7,9 \pm 0,4$ $( \pm 2 \sigma) \mathrm{Ma}$ (Mioceno Tardío) en fenocristales de plagioclasa. Esta edad, junto con su morfología, espesor, nivel de emplazamiento y relaciones de corte (intruye a cuerpos de diorita y es cortado por pórfidos dacíticos), permite inferir que el pórfido riodacítico corresponde a una variación lateral, de textura porfírica y con mayor contenido de ortoclasa, de la granodiorita.

Las edades obtenidas coinciden con el inicio de un episodio deformativo y de emplazamiento de intrusivos documentados en ambas vertientes de la Cordillera Principal a la latitud de Chile central, para el Mioceno Tardío-Plioceno Temprano, en el cual se incluyen los principales eventos de intrusión y mineralización de las zonas de El Teniente y de Río Blanco-Los Bronces (Skewes y Stern, 1995; Kurtz et al., 1995, 1997; Ramos, 1996; Ramos et al., 1996a, b; Godoy et al., 1999; Deckart et al., 2003, y otros).

\section{Estructuras de alto ángulo}

Se observan dos estructuras de importancia regional en la zona de estudio: el Corrimiento El Fierro y el Sistema de Fallas Infiernillo-Los Cipreses.

\subsection{El Corrimiento El Fierro}

Se localiza en la parte oriental del área de estudio. El plano de falla muestra un rumbo aproximado N-S y un manteo de $45-50^{\circ}$ al oeste (Figs. 5 y 7 A). Fue definido por Davidson (1971) como una falla inversa de alto ángulo, mediante la cual rocas volcánicas de la Formación Colimapu (Cretácico Tardío), cabalgan a las unidades jurásicas y neocomianas. Sin embargo, como ha sido expuesto anteriormente, las rocas asignadas a la Formación Colimapu facies volcánica, en el área de estudio, corresponderían al miembro oriental de la Formación Abanico. En la quebrada de la Vega Chica, pliegues de arrastre con vergencia oriental, desarrollados en los estratos basales del miembro oriental, permiten interpretar que esta unidad fue alzada sobre formaciones mesozoicas (Baños del Flaco y Río Damas), las cuales se encuentran intensamente plegadas (Figs. 5 y 7A). Davidson (1971) había descrito pliegues de arrastre indicadores del mismo tipo de movimiento, tanto en calizas de la Formación Baños del Flaco como en areniscas equivalentes a las unidades A2 y B1 del miembro oriental de la Formación Abanico, en el sector del Cajón del Fierro, inmediatamente al norte de la quebrada de la Vega Chica. El hecho de que las rocas del bloque alzado sean más jóvenes que las del bloque yacente, permite inferir un movimiento normal previo para esta estructura, cuya magnitud fue mayor a la del movimiento inverso que le sucedió.

En la ladera norte del valle del río Pellejo, cerca de su confluencia con la quebrada de la Vega Chica, se observaron estratos de crecimiento en los niveles sedimentarios basales del miembro oriental. Los depósitos forman un abanico abierto hacia el este, hasta ser interrumpidos por el Corrimiento El Fierro, el cual como se ha detallado anteriormente, corresponde a una falla de alto ángulo con manteo al oeste (Fig. 7B). La geometría descrita permite interpretar los depósitos como sinextensionales, depositados sobre el bloque colgante del Corrimiento El Fierro, en un período en que este último habría actuado como una falla normal. Se infiere, entonces, que esta actuó como una falla de borde de cuenca desde el Eoceno Tardío-Oligoceno Temprano (edad inferida para los estratos de crecimiento en los niveles basales del miembro oriental), la cual, por lo tanto, estuvo activa desde los inicios de la depositación de la Formación Abanico en la zona de estudio. Se repite, entonces, la situación documentada por diversos autores en distintos puntos de la Cordillera Principal al norte de esta zona (Godoy, 1991; Charrier et al., 1996). 
FIG. 7. A. Vista hacia el norte desde la confluencia entre la quebrada de la Vega Chica y el río Pellejo. Se observa nítidamente el Corrimiento El Fierro (línea segmentada), manteando 45$50^{\circ}$ al oeste. Los niveles basales del miembro oriental (MOR) aparecen en el bloque alzado, mientras que en el bloque yacente, se observan las formaciones mesozoicas Baños del Flaco (BF) y Río Damas (RD), manteando $70-80^{\circ}$ al oeste. B. Vista hacia el norte desde la ladera sur del valle del río Pellejo. En el extremo derecho aparece la traza del Corrimiento El Fierro (línea segmentada). En primer plano, se observan estratos de crecimiento en niveles basales del miembro oriental (MOR), acuñando al oeste.
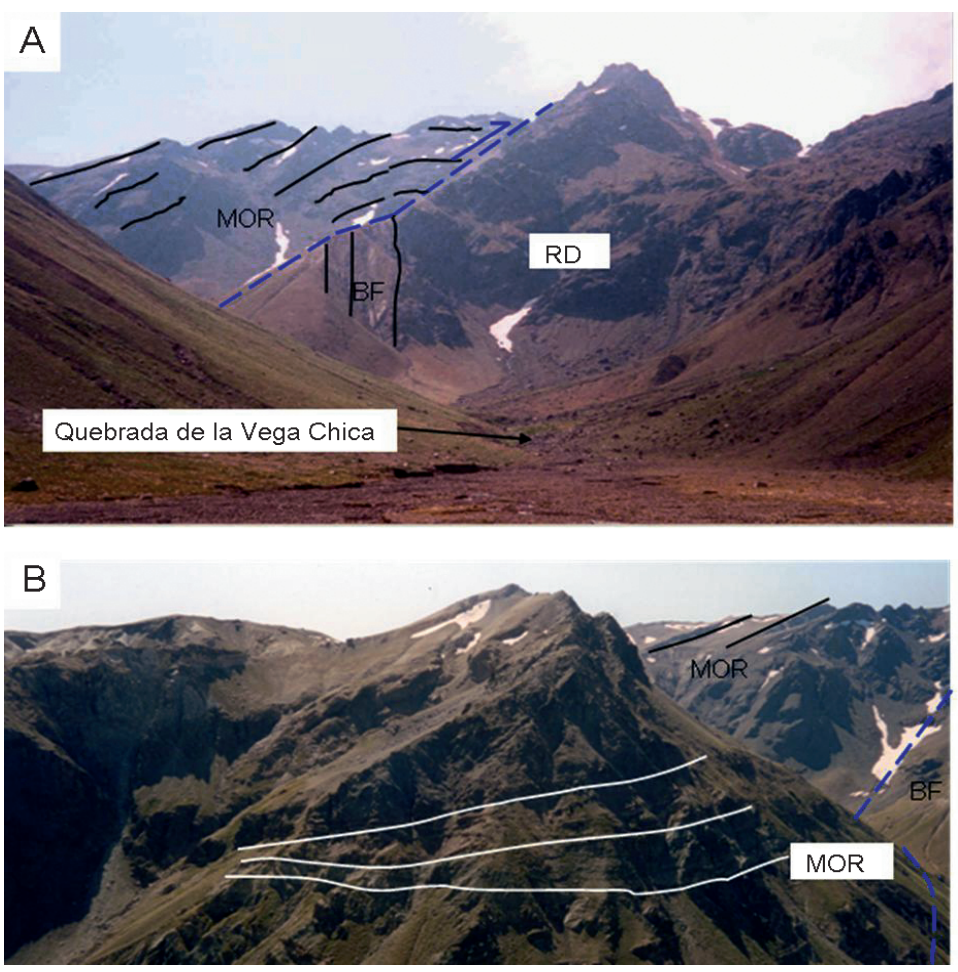

Posteriormente, el Corrimiento El Fierro fue reactivado en modo inverso, ocasionando alzamiento, erosión y plegamiento de los depósitos de la Formación Abanico, hasta la situación actual, en que aparecen expuestos los niveles basales del miembro oriental. La inversión no fue total, ya que las rocas del bloque alzado son más jóvenes que las expuestas en el bloque yacente. El Corrimiento El Fierro corresponde al segmento sur de una estructura de carácter regional, reconocida hacia el norte de la región estudiada en las hoyas de los ríos Cachapoal y Maipo, denominada sistema de falla El Diablo-Las Leñas-El Fierro (Charrier et al., 2002; Fock et al., 2005, 2006). Trabajos inéditos desarrollados por Codelco Chile y por su filial Exploraciones Mineras Andinas S.A. (Castelli, 1999'1 Iriarte y Sellés, 2000²; Piquer, $2007^{3}$ ), han permitido proponer estructuras equivalentes al menos hasta la latitud del yacimiento Los Pelambres ( $\left.31^{\circ} 43^{\prime} \mathrm{S}-70^{\circ} 29^{\prime} \mathrm{O}\right)$. Estudios recientes han demostrado que esta estructura es sísmicamente activa (Farías et al., 2006).

\subsection{El Sistema de fallas Infiernillo-Los Cipreses}

Está constituido por un conjunto de estructuras menores relacionadas entre sí, que se observan en la parte occidental del área de estudio (Fig. 2). Tienen un rumbo promedio $\mathrm{N} 20^{\circ} \mathrm{E}$ en la parte sur y N-S en la parte norte. Este sistema estructural corresponde a la prolongación hacia el sur de las fallas inversas de vergencia oriental mencionadas por Zapatta (1995) al oeste del Corrimiento El Fierro, en el sector del Portezuelo El Baule.

El sistema de fallas coincide espacialmente con la franja de dioritas y pórfidos dacíticos, y controla el emplazamiento de diques que mantean $65-70^{\circ} \mathrm{O}$, valor que puede considerarse como una aproximación del manteo del sistema de fallas. Además, estas estructuras constituyen el límite oriental de los cuerpos intrusivos mayores (granodiorita y pórfido riodacítico). Se detectó la presencia de cataclasitas en la traza de estas fallas, afectando tanto a las rocas intrusivas como a las volcánicas, evidenciando algún

\footnotetext{
${ }^{1}$ Castelli, J. 1999. Geología de exploración básica generativa entre el río Yeso y el paso Los Libertadores. Informe (inédito), archivo técnico, CODELCO Chile. ${ }^{2}$ Iriarte, S.; Sellés, D. 2000. Geología entre el paso Los Libertadores y Mina Pelambres. Informe (inédito), archivo técnico, CODELCO Chile.

${ }^{3}$ Piquer, J. 2007. Geología del Distrito Andina, fase III, escala 1:25.000. Informe (inédito), archivo técnico, CODELCO Chile-EMSA.
} 
grado de actividad postmagmática. Además, se observó que las intercalaciones sedimentarias rojas presentes en las unidades 2 y 4 del miembro occidental de la Formación Abanico (Fig. 4), se encuentran presentes solo al este del sistema de fallas, y en las cercanías de su traza forman pequeños pliegues de arrastre con vergencia oriental. Del mapeo geológico y las secciones estructurales (Figs. 2 y 5), se interpreta que las lavas andesíticas de la Formación Abanico aumentan bruscamente de espesor al oeste del Sistema de Fallas Infiernillo-Los Cipreses. La geocronología de las unidades volcánicas indica que al oeste del sistema de fallas la depositación de flujos de lava andesíticos se inició al menos en el Oligoceno Tardío (Hurtado, 2003), mientras que al este las unidades lávicas son de edad Mioceno Temprano a Medio (miembro occidental de la Formación Abanico). Finalmente, la relevancia de esta estructura se ve respaldada por la modelación magnética de secciones geológicas (descrita en capítulo siguiente), la cual es coherente con la interpretación anterior.

Estudios magnetotelúricos desarrollados recientemente a lo largo del valle del río Teno en el marco del Proyecto Anillo ACT N¹8 (Díaz, 2007), han permitido reconocer la expresión de estas fallas en profundidad, confirmando su importancia regional y como conductos favorables para canalizar el ascenso de magmas. Geoeléctricamente estas fallas se representan como ambientes conductores (10-30 ohm-m) subverticales que alcanzan profundidades de varios kilómetros (Fig. 8).

De todo lo anterior, se infiere que el Sistema de Fallas Infiernillo-Los Cipreses fue una importante estructura de borde de cuenca, con manteo al oeste, la cual controló la ubicación de depocentros donde se acumularon las volcanitas de la Formación Abanico, durante el Oligoceno-Mioceno Medio. Es posible que haya estado activa desde el Eoceno, si se acepta su correlación con las estructuras reconocidas más al norte por Zapatta (1995), las cuales controlaron la depositación de los niveles más antiguos documentados en la Formación Abanico. Su salto mínimo, estimado de las secciones geológicas (Fig. 5), es del orden de un kilómetro.

En el Mioceno Tardío, esta falla de alto ángulo sirvió como conducto por el cual ascendieron a niveles superiores de la corteza los magmas que formaron los intrusivos de Infiernillo-Los Cipreses, los cuales se emplazaron hacia el oeste de la estructura. La edad de los intrusivos mencionados corresponde, como ya ha sido discutido, al inicio del episodio principal de deformación y alzamiento ocurrido en los Andes de Chile central. Esto, junto con la existencia de pliegues de arrastre indicadores de movimiento inverso en sedimentitas afectadas por las fallas y su correlación con estructuras de tipo normal reactivadas

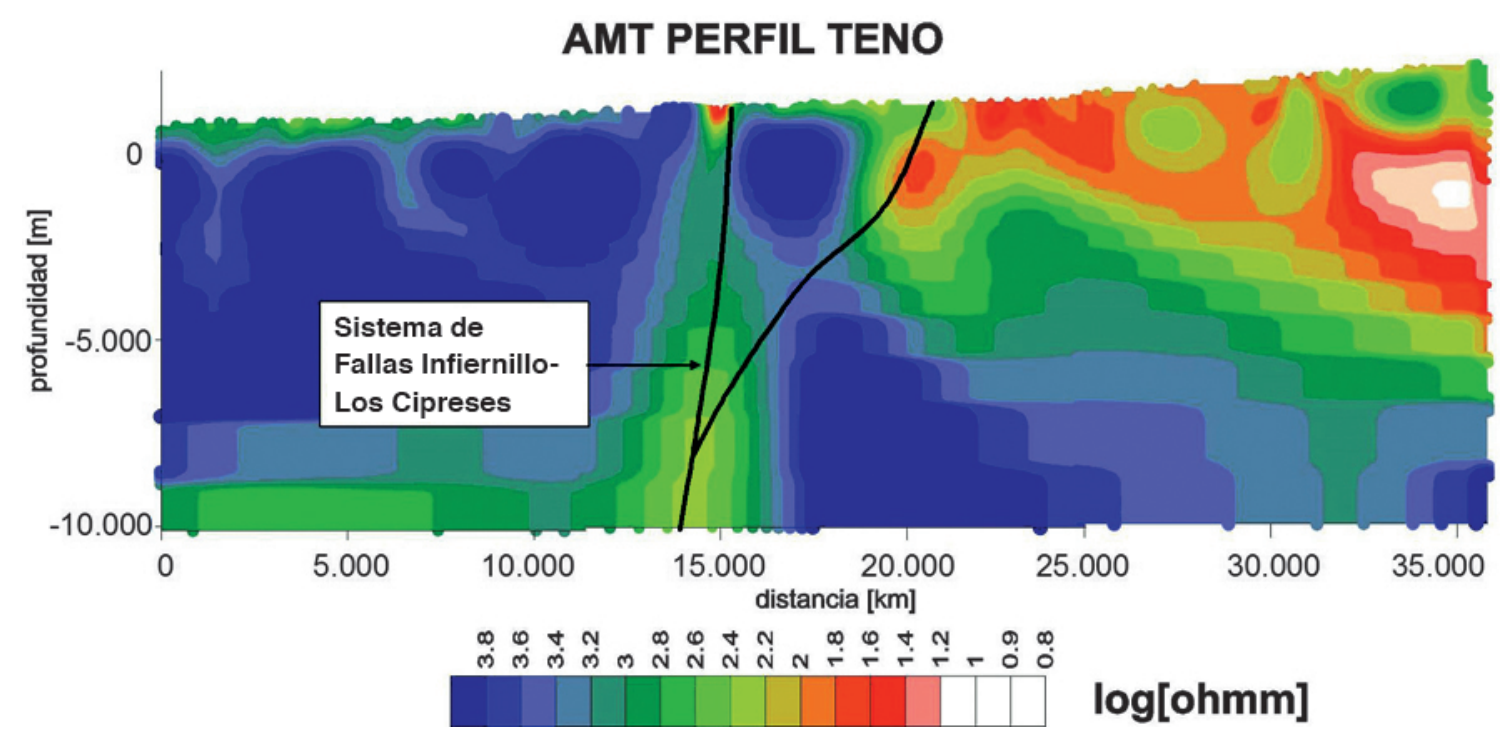

FIG. 8. Perfil AMT a lo largo del valle del río Teno. Se muestra la ubicación de la zona de falla Infiernillo-Los Cipreses, la cual se manifiesta como un marcado conductor eléctrico subvertical de al menos $10 \mathrm{~km}$ de profundidad. Modificado de Díaz (2007). 
en modo inverso descritas por Zapatta (1995) en el sector de Baños del Flaco, permite inferir que las fallas de Infiernillo-Los Cipreses, al igual que el Corrimiento El Fierro, fueron reactivadas en modo inverso durante el episodio deformativo del Mioceno Tardío-Plioceno Temprano.

Todo lo anterior es concordante con los modelos mecánicos relativos a la reactivación en modo inverso de fallas de alto ángulo (Sibson, 1985, 2000, 2001; Sibson et al., 1988), que predicen que para que esta se produzca es necesaria la existencia de una presión de fluidos supralitostática (lo que se vería facilitado en una falla que controle la circulación de magmas). Esto a su vez debiera verse reflejado en la existencia de estructuras de extensión subhorizontales, cuya formación se ve favorecida en presencia de un régimen tectónico compresivo ( $\sigma 1$ horizontal, $\sigma 3$ vertical y según el punto anterior menor a la presión de fluidos, Fig. 9). Estas condiciones se cumplen para el Mioceno Tardío en la zona de Infiernillo-Los Cipreses, ya que se observa un fuerte control estructural sobre el magmatismo, junto a grandes cuerpos intrusivos subhorizontales (granodiorita y pórfido riodacítico), para cuyo emplazamiento fue necesaria la generación de espacios mediante estructuras dilatacionales desarrolladas en el contacto entre distintos niveles del miembro occidental de la Formación Abanico. Además, como ya ha sido mencionado, los intrusivos coinciden temporalmente con un importante evento tectónico compresivo.

Al producirse el fallamiento, el 'stress' efectivo en la zona de falla disminuye drásticamente, lo que permite la circulación de fluidos a través de ella, su ascenso a niveles superiores de la corteza, y su emplazamiento en forma de lentes subhorizontales, en este caso en planos estratigráficos de la Formación Abanico. La falla se encuentra a un alto ángulo con respecto a $\sigma 1$, por lo cual el ascenso de fluidos se produciría principalmente a través de redes de 'jogs' dilatacionales y fracturas de tensión, asociadas al plano de falla principal (Fig. 9). Este mecanismo ha sido propuesto por Hill (1977) y Sibson $(1985,2001)$ como válido, en distintos niveles de la corteza, para el ascenso de fluidos hidrotermales, hidrocarburos y magmas. Tosdal y Richards (2001) también postulan que el ascenso de magmas, cuando hay sobrepresión (por ejemplo, durante episodios compresivos mayores), se puede producir a través de fallas de alto ángulo, hacia espacios dilatacionales, impulsados por el fuerte gradiente hidrodinámico. Ellos también afirman que, si bien en teoría los diques alimentadores se orientan paralelos a $\sigma 1$ y perpendiculares a $\sigma 3$, ante la existencia de fallas preexistentes y grandes presiones de fluidos se pueden formar diques fuertemente desorientados. Este último sería el caso de los diques dacíticos y dioríticos observados en terreno, los cuales se orientan paralelos al Sistema de Fallas Infiernillo-Los Cipreses (N-S a N20 $\left.{ }^{\circ} \mathrm{E}\right)$, perpendiculares a la orientación de $\sigma 1$ en Chile central durante el Mioceno Tardío-Plioceno (Lavenu y Cembrano, 1999).

En Chile, un mecanismo similar de ascenso y emplazamiento de magmas, donde el primero se produce asociado a fallas normales de alto ángulo reactivadas en modo inverso, ha sido propuesto por Skármeta y Castelli (1997) para el intrusivo de Torres del Paine, por Skármeta et al. (2003) y Amilibia y Skármeta (2003) para el sistema de intrusivos del sector de Chuquicamata, y por Cornejo et al. (2003) para el magmatismo del Paleoceno Temprano en la Precordillera andina entre los $24^{\circ}$ y los $27^{\circ} \mathrm{S}$. En Chile central, Godoy (1998) describió intrusiones sintectónicas miocenas que afloran en los valles de Aconcagua, Maipo y Cachapoal, en este último caso asociadas al Corrimiento El Fierro.

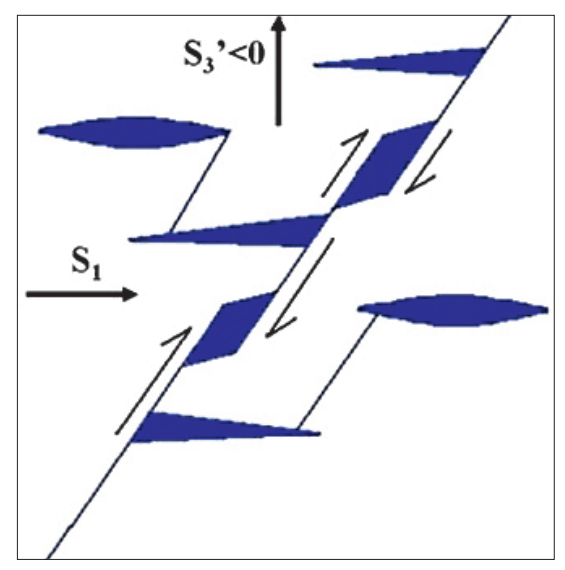

FIG. 9. Esquema que muestra las condiciones necesarias para la reactivación en modo inverso de fallas de alto ángulo, las cuales se cumplen en su totalidad para la zona de falla Infiernillo-Los Cipreses. El esfuerzo principal $\sigma_{1}$ es subhorizontal (régimen tectónico compresivo), mientras que $\sigma_{3}{ }^{\prime}=\sigma_{3}-P_{\mathrm{f}}<0$. Es decir, la presión de fluidos es superior al esfuerzo vertical (supralitostática). Esto permite la generación de espacios dilatacionales subhorizontales que pueden actuar como reservorios de magmas, unidos por diques alimentadores paralelos al plano de falla principal. 


\section{Modelación magnética}

Las mediciones de susceptibilidad magnética se realizaron en terreno sobre cada tipo litológico con un susceptibilimetro marca Exploranium, modelo KT-9 Kapameter. Se efectuaron diez medidas de susceptibilidad magnética por punto, para obtener un valor medio representativo del afloramiento. Se tomaron en total 1.540 medidas, asociadas a 154 puntos. Posteriormente los puntos se agruparon por tipo litológico para así obtener los valores promedio de cada unidad (Tabla 2).

Así, a cada una de las unidades presentes en las secciones geológicas (Fig. 5) se le asignó una susceptibilidad magnética media. Mediante el programa de modelación magnética ModelVision de ENCOM, se modeló la forma que tendría la anomalía magnética sintética producto de la definición de cuerpos magnetizados que representan las unidades geológicas de cada sección. Finalmente, estos perfiles teóricos

TABLA 2. SUSCEPTIBILIDADES PROMEDIOY NÚMERO DE MEDIDAS POR UNIDAD LITOLÓGICA.*

\begin{tabular}{lcr}
\hline \multicolumn{1}{c}{ Litología } & $\begin{array}{c}\text { Suc. Prom. } \\
(\text { SI*10-3) }\end{array}$ & $\begin{array}{c}\mathbf{N}^{\mathbf{0}} \\
\text { medidas }\end{array}$ \\
\hline Granodiorita, tonalita & 19.989 & 120 \\
Diorita & 46.007 & 90 \\
Pórfidos dacíticos & 4.952 & 110 \\
Miembro occ-Abanico volcánico & & \\
metamorfismo de contacto & 73.603 & 270 \\
Miembro occidental- & & \\
Abanico volcánico & 23.364 & 280 \\
Miembro occidental- & 3.632 & 150 \\
Abanico sedimentario & 6.965 & 90 \\
'Ocoíta' & & \\
Miembro oriental-Abanico tobáceo & 4.533 & 260 \\
y sedimentario & 9.611 & 50 \\
Miembro oriental-Abanico lávico & 0.802 & 60 \\
Formación Río Damas & 17.865 & 10 \\
Intrusivo andesítico & 17.515 & 20 \\
Filón-manto diorítico & 13.563 & 30 \\
Pórfido riodacítico & & $\mathbf{1 . 5 4 0}$ \\
TOTAL medidas & & \\
\hline & & \\
\hline
\end{tabular}

* Las lavas del miembro occidental de la Formación Abanico se separaron en proximales y distales a cuerpos intrusivos, ya que en las cercanías de estos mostraban una respuesta magnética particular debido a la presencia de magnetita secundaria. se ajustaron a la señal aeromagnética observada en la zona de estudio. De acuerdo a las similitudes y diferencias entre los perfiles aeromagnéticos teóricos y reales, se evaluaron las hipótesis presentadas en las secciones geológicas, como por ejemplo las relativas al tamaño, forma y disposición en profundidad de cuerpos intrusivos a los que se asocian zonas magnetitizadas; o acerca de la profundidad e importancia regional de estructuras que ponen en contacto unidades de diferentes respuestas magnéticas. Así, esta herramienta aportó un mayor grado de confiabilidad a la extensión a profundidad de las observaciones de superficie.

El resultado final de la modelación magnética se muestra en la figura 10. A continuación se explican algunos detalles particulares acerca de las secciones modeladas.

En la sección A-A' se observa un 'peak' de gran amplitud y longitud de onda relativamente corta. El único cuerpo con tamaño suficientemente grande y valores de susceptibilidad magnética suficientemente altos para explicar un 'peak' de esa amplitud, es una zona de metamorfismo de contacto que afecta a rocas volcánicas de la Formación Abanico, formando un halo en torno a los cuerpos intrusivos, el cual es especialmente intenso sobre el techo de los mismos, observándose la asociación biotita + magnetita+actinolita+cuarzo. Spichiger (1993) ya había inferido, sobre la base del estudio de la carta aeromagnética de la zona y a observaciones de terreno, que las anomalías de alta amplitud y frecuencia observadas en la región corresponden a zonas magnetitizadas de la Formación Abanico.

En las secciones de más al sur, el 'peak' producido por la magnetita secundaria desaparece debido al nivel de erosión más profundo, que expone en superficie cuerpos de pórfido dacítico con alteración cuarzosericítica, los cuales tienen susceptibilidad magnética cercana a cero y cortan la zona magnetitizada.

En todas las secciones se observa, además, otro rasgo de primera importancia: inmediatamente al oeste de los intrusivos de Infiernillo-Los Cipreses (y de la zona magnetitizada asociada a ellos) se produce un importante alto magnético, de gran amplitud y longitud de onda. Esta forma de la curva es coherente con la modelación directa de las observaciones de terreno, sobre la base de las cuales se infería un brusco aumento de espesor de las lavas de la Formación Abanico al oeste del Sistema de Fallas Infiernillo-Los Cipreses. Esto porque el basamento de dicha unidad 
(las formaciones mesozoicas y posibles niveles piroclásticos del miembro oriental) tiene valores de susceptibilidad magnética cercanos a cero. La hipótesis de un aumento de espesor de la Formación Abanico se ve apoyada por la correlación de estas estructuras con las descritas por Zapatta (1995) en el sector de Baños del Flaco, al oeste de las cuales también aumentan de espesor los depósitos de la mencionada unidad. Como se ve en las secciones modeladas, la forma de la curva corresponde casi perfectamente a la respuesta que daría un aumento de alrededor de $1.000 \mathrm{~m}$ en la potencia de la secuencia andesítica de la Formación Abanico (Fig. 10).

\section{Evolución tectono-estratigráfica}

\subsection{Eoceno Tardío-Mioceno Temprano, exten- sión y volcanismo bimodal}

Durante este período comenzaría la depositación de las unidades basales (conglomerados, litarenitas e intercalaciones de lavas andesíticas) del miembro oriental de la Formación Abanico. Estos niveles son afectados por fallas normales, cuya actividad, sobre la base de los estratos de crecimiento observados, se interpreta como sindepositacional. Algunas de estas estructuras corresponden al actual Corrimiento El
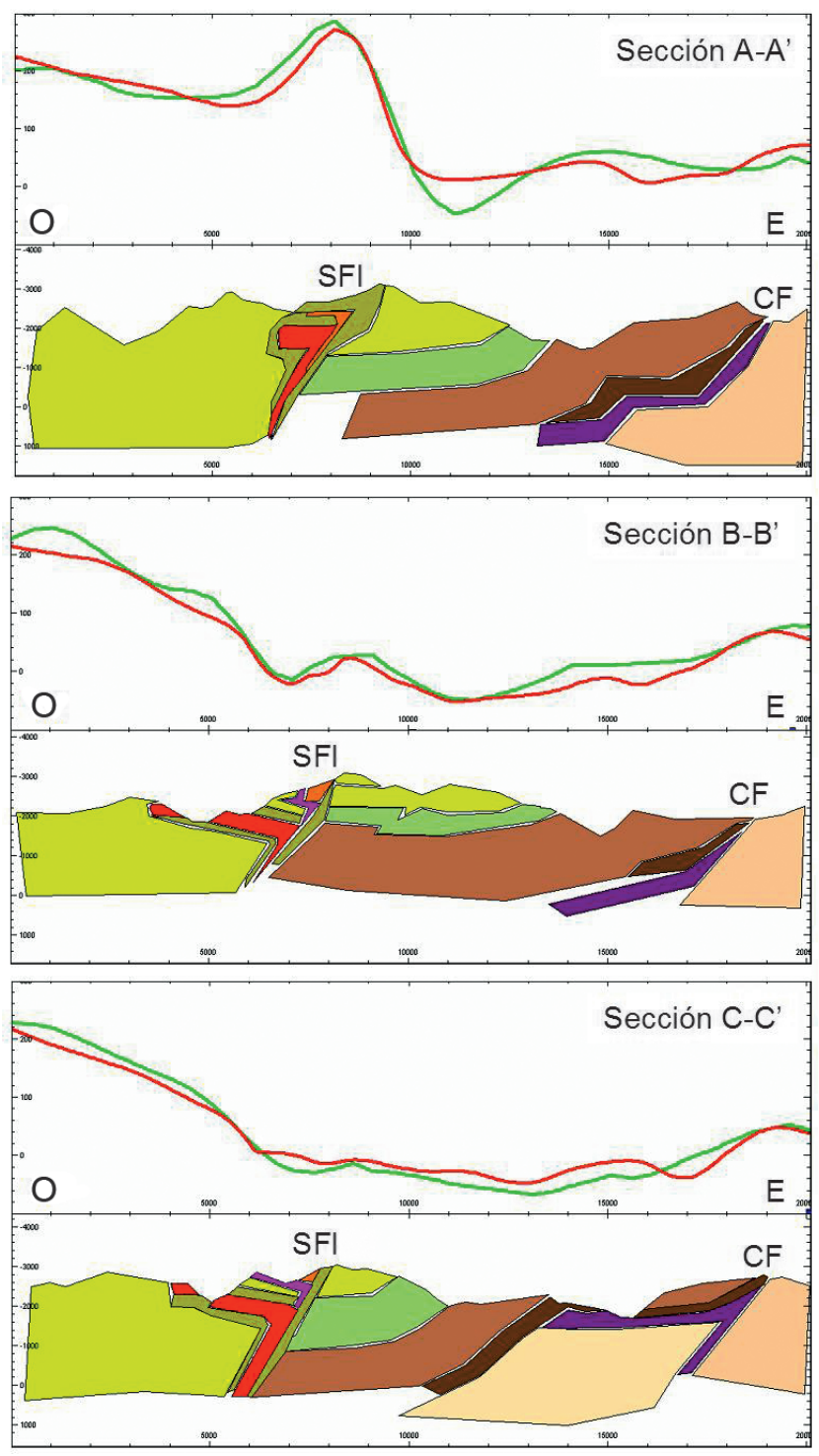

\section{LEYENDA}

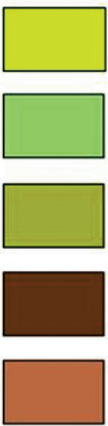

Formación Abanico, miembro occidental volcánico

Formación Abanico, miembro occidental sedimentario

Formación Abanico volcánico con metamorfismo de contacto

Formación Abanico, miembro oriental lávico

Formación Abanico, miembro oriental tobáceo y sedimentario

\section{Formación Río Damas}

Mesozoico sedimentario indiferenciado

Pórfido dacítico

Granodiorita

Diorita

Ocoíta

FIG. 10. Resultados de la modelación magnética de las secciones geológicas presentadas en la figura 5. Cada unidad litológica aparece representada por un cuerpo (ver leyenda), al cual se le asignó la susceptibilidad magnética correspondiente según la tabla 2. Se indica la ubicación de las estructuras principales: SFI: Sistema de Fallas Infiernillo-Los Cipreses; CF: Corrimiento El Fierro. Se muestran además las curvas de magnetismo real (color verde) y modelado (color rojo). 
Fierro y al Sistema de Fallas Infiernillo-Los Cipreses, las cuales controlan la ubicación de depocentros en los que se acumularon las volcanitas de la Formación Abanico. Al este de la última estructura, comienzan a cobrar importancia eventos volcánicos explosivos, representados por flujos piroclásticos félsicos, los que en un comienzo aparecen intercalados con las lavas andesíticas, pero luego pasan a constituir la única manifestación volcánica presente en la zona. Se depositaron hasta $1.700 \mathrm{~m}$ de rocas piroclásticas. Un evento similar, aunque de menor magnitud (hasta $1.000 \mathrm{~m}$ de rocas piroclásticas intercaladas con niveles sedimentarios), ha sido documentado para la base de la Formación Abanico en la zona de Baños del Flaco (Fig. 1), y también fue considerado como depositado en un ambiente extensional, asociado a la apertura de la Cuenca de Abanico (Zapatta, 1995; Charrier et al., 1990, 1996). Al oeste del Sistema de Fallas Infiernillo-Los Cipreses, en cambio, no se encuentran depósitos piroclásticos equivalentes y al menos desde el Oligoceno Tardío comenzó la acumulación de una potente secuencia de flujos de lava andesíticos.

\subsection{Mioceno Temprano a Medio, extensión y volcanismo andesítico}

Hacia el techo del miembro oriental, durante el Mioceno Temprano, comienzan a aparecer intercalaciones de lavas andesíticas, además de niveles de conglomerados, areniscas y lutitas. Esto indica una disminución de los aportes volcánicos en la zona de estudio, lo que permitió la depositación de sedimentos finos y un cambio en el carácter del mismo, pasando a ser rápidamente las lavas andesíticas el único producto volcánico observado. Se extiende así al bloque oriental del Sistema de Fallas Infiernillo-Los Cipreses la extrusión de productos más primitivos, principalmente andesitas de piroxeno, cuyo ascenso se produce a través de una corteza continental adelgazada por la extensión. Durante el Mioceno Temprano a Medio, se depositaron al menos $1.500 \mathrm{~m}$ de lavas andesíticas, con delgadas intercalaciones sedimentarias fluviales.

De lo anterior se desprende que en el bloque occidental del Sistema de Fallas Infiernillo-Los Cipreses la depositación de lavas andesíticas se inició considerablemente antes que en el bloque oriental, repitiéndose la situación descrita en torno a estructuras equivalentes más al norte, al oeste de Baños del Flaco (Zapatta, 1995; Charrier et al., 2002).

\subsection{Mioceno Tardío, inversión tectónica y plu- tonismo}

Se interpreta que durante el Mioceno Tardío, tanto el Corrimiento El Fierro como el Sistema de Fallas Infiernillo-Los Cipreses fueron reactivados en modo inverso, iniciándose el alzamiento y erosión de los depósitos de la cuenca. Además, se produjo deformación pero solo en las inmediaciones de las estructuras, las que, por tener alto ángulo de manteo, tienen poco acortamiento horizontal asociado.

Durante el Mioceno Tardío se produjo (sintectónicamente) el ascenso de importantes volúmenes de magma mediante diques fuertemente desorientados, perpendiculares a $\sigma 1$, que intruyeron a través de la zona de debilidad asociada al Sistema de Fallas Infiernillo-Los Cipreses, los que evolucionaron desde una composición diorítica, hacia productos más diferenciados como granodioritas y pórfidos dacíticos y riodacíticos. El emplazamiento ocurrió hacia el oeste de los canales de ascenso de magmas, en el bloque alzado de la falla, principalmente en discontinuidades subhorizontales asociadas a estratificación de la Formación Abanico, cuya apertura se vio favorecida por la existencia de un régimen tectónico compresivo ( $\sigma 1$ subhorizontal y $\sigma 3$ vertical).

\section{Conclusiones}

Se registró la existencia de un importante episodio volcánico explosivo cenozoico (miembro oriental de la Formación Abanico), durante el cual se depositaron hasta $1.700 \mathrm{~m}$ de rocas piroclásticas. En el resto de la zona de estudio, la Formación Abanico muestra las litologías que caracterizan a dicha formación en todo el sector andino de Chile central, predominando las lavas andesíticas de piroxeno, con intercalaciones lenticulares de sedimentos fluviales y lacustres. Se demuestra que las intercalaciones sedimentarias rojas, antiguamente consideradas típicas de la Formación Colimapu (González y Vergara, 1962; Davidson, 1971), en la zona de estudio están incluidas en la Formación Abanico y, en ocasiones, se encuentran intercaladas con las lavas andesíticas (Fig. 4). Esto coincide con las conclusiones obtenidas por Hurtado (2003) en un contexto estratigráfico similar, en un área ubicada unos $30 \mathrm{~km}$ al SO de la zona considerada en este trabajo. 
Los cuerpos intrusivos de Infiernillo-Los Cipreses corresponden a: dioritas; granodioritas datadas en 7,8 $\pm 0,4 \mathrm{Ma}$ (K-Ar en biotita); pórfidos riodacíticos datados en 7,9 $\pm 0,4 \mathrm{Ma}$ (K-Ar en fenocristales de plagioclasa), y pórfidos dacíticos. Los pórfidos riodacíticos probablemente correspondan a un equivalente lateral de la granodiorita.

Se observan dos sistemas estructurales mayores en la zona de estudio: el Corrimiento El Fierro, y el Sistema de Fallas Infiernillo-Los Cipreses. El Corrimiento El Fierro actuó durante el Eoceno Tardío-Mioceno Medio como una falla normal de borde de cuenca, que controló desde sus inicios la depositación de los productos volcánicos y sedimentarios de la Formación Abanico. Con posterioridad fue reactivada en modo inverso, probablemente durante el Mioceno Tardío. La inversión no fue total, ya que en la actualidad yuxtapone a las unidades basales del miembro oriental en el bloque alzado con las formaciones mesozoicas en el bloque yacente. El Sistema de Fallas Infiernillo-Los Cipreses corresponde a una estructura paralela al Corrimiento El Fierro, originalmente de tipo normal con manteo al oeste, que también controló la depositación de la Formación Abanico. Se infiere, igualmente, que fue reactivada en modo inverso durante el Mioceno Tardío.

La confección de secciones geológicas y su posterior modelación magnética permitió estimar que el espesor de los depósitos volcánicos andesíticos de la Formación Abanico se incrementa en alrededor de $1.000 \mathrm{~m}$ al oeste del Sistema de Fallas Infiernillo-Los Cipreses, sugiriendo la existencia en ese lugar de un importante depocentro de las cuencas volcanotectónicas del Eoceno Tardío-Mioceno Medio. La información geocronológica disponible permite señalar que en el mencionado depocentro, la acumulación de lavas andesíticas se inició alrededor de $10 \mathrm{Ma}$ antes que en la región ubicada inmediatamente al este de la mencionada estructura. Se infiere que este sistema de fallas tendría una importancia regional y se la correlaciona con estructuras de similar rumbo, manteo y vergencia, documentadas por Zapatta (1995) al oeste de Baños del Flaco en el Portezuelo de El Baule, inmediatamente al norte del área de estudio. En perfiles regionales AMT, esta zona de falla destaca como un notable conductor eléctrico subvertical, de varios kilómetros de profundidad. Las evidencias descritas en este trabajo permiten interpretar que durante la inversión de la cuenca asociada al evento compresivo del Mioceno Tardío-Plioceno, esta es- tructura habría actuado como el conducto por el cual se produjo el ascenso recurrente de distintos pulsos de magmas que al emplazarse en discontinuidades subhorizontales de la corteza superior (estratificación de la Formación Abanico), en el bloque alzado de la falla, dieron origen a los intrusivos de InfiernilloLos Cipreses. Este mecanismo es coherente con los modelos mecánicos vigentes que modelan el ascenso y emplazamiento de fluidos en general y de magmas en particular, a través de la corteza superior (Hill, 1977; Sibson, 1985, 2001; Tosdal y Richards, 2001).

\section{Agradecimientos}

Este artículo se basa en la memoria de título del primer autor (Piquer, 2004), completada en el Departamento de Geología de la Universidad de Chile. Esta fue financiada íntegramente por la Gerencia Corporativa de Exploraciones de Codelco, a la cual se agradece el correspondiente permiso de publicación. Se agradece también al grupo de exploraciones de Codelco-EMSA que trabajan en la franja Mio-pliocena, en especial a O. Rivera, por las numerosas discusiones que permitieron mejorar este artículo. Igualmente, se agradece a los editores de la revista, por sus valiosos comentarios y sugerencias. Las conclusiones de este trabajo han sido complementadas por los resultados del Proyecto Anillo ACT N 18.

\section{Referencias}

Aguirre, L. 1960. Geología de los Andes de Chile Central, Provincia de Aconcagua. Instituto de Investigaciones Geológicas, Boletín 9: 70 p.

Amilibia, A.; Skármeta, J. 2003. La inversión tectónica de la Cordillera de Domeyko en el norte de Chile y su relación con la intrusión de sistemas porfídicos de Cu-Mo. In Congreso Geológico Chileno, No. 10, Actas, CD-Rom, Sesión Temática 2.

Bevins, R.; Robinson, D.; Aguirre, L.; Vergara, M. 2003. Episodic burial metamorphism in the Andes-A viable model? Geology 31: 705-708.

Charrier, R. 1981. Geologie der chilenischen Hauptkordillere zwischen 34³0' südlicher Breite und ihre tektonische, magmatische und paleogeographische Entwicklung. Berliner Geowissenschaftliche Abhandlungen (A) 36: $270 \mathrm{p}$.

Charrier, R.; Wyss, A.; Norell, M.; Flynn, J.; Novacek, M.; McKenna, M.; Swisher, C.; Frassinetti, D.; Salinas, P. 1990. Hallazgo de mamíferos fósiles del Terciario Inferior en el sector de Termas del Flaco, Cordillera Principal, Chile Central: implicaciones paleontológi- 
cas, estratigráficas y tectónicas. In Simposio sobre el Terciario de Chile, No. 2, Actas 1: 73-84.

Charrier, R.; Wyss, A.R.; Flynn, J.; Swisher, C.C. III, Spichiger, S.; Zapatta, F. 1994. Nuevos antecedentes estratigráficos y estructurales para las Formaciones Coya-Machalí y Abanico, entre $33^{\circ} 50^{\prime}$ y $35^{\circ} \mathrm{S}$, Cordillera Principal Chilena. In Congreso Geológico Chileno, No. 7, Actas: 1316-1319.

Charrier, R.; Wyss, A.; Flynn, J.; Swisher, C.; Norell, M.; Zapatta, F.; McKenna, M.; Novacek, M. 1996. New evidence for Late Mesozoic-Early Cenozoic evolution of the Chilean Andes in the Upper Tinguiririca Valley $\left(35^{\circ} \mathrm{S}\right)$, Central Chile. Journal of South-American Earth Sciences 9 (5-6): 393-422.

Charrier, R.; Baeza, O.; Elgueta, S.; Flynn, J.; Gans, P.; Kay, S.; Muñoz, N.; Wyss, A.; Zurita, E. 2002. Evidence for Cenozoic extensional basin development and tectonic inversion south of the flat-slab segment, southern Central Andes, Chile ( $33^{\circ}-36^{\circ}$ S.L.). Journal of South-American Earth Sciences 15: 117-139.

Charrier, R.; Bustamante, M.; Comte, D.; Elgueta, S.; Flynn, J.; Iturra, N.; Muñoz, N.; Pardo, M.; Thiele, R.; Wyss, A. 2005. The Abanico Extensional Basin: Regional extension, chronology of tectonic inversion, and relation to shallow seismic activity and Andean uplift. Neues Jahrbuch für Geologie und Paläontologie Abh. 236 (1-2): 43-47.

Charrier, R.; Flynn, J.; Wyss, A.; Croft, D. En prensa. Mamíferos terrestres cenozoicos pre-pleistocénicos y sus implicaciones geológicas. In Vertebrados fósiles de Chile (Rubilar, D.; Sallaberry, M.L.; editors), Capítulo 17.

Cornejo, P.; Matthews, S.; Pérez de Arce, C. 2003. The ' $\mathrm{K}-\mathrm{T}$ ' compressive deformation event in northern Chile $\left(24-27^{\circ} \mathrm{S}\right)$. In Congreso Geológico Chileno, No. 10, Actas, CD-Rom, Sesión Temática 1. Concepción.

Davidson, J. 1971. Contribución al estudio geológico de los Andes Meridionales Centrales: Geología del área de las Nacientes del Teno, Provincia de Curicó. Memoria de Título (Inédito), Departamento de Geología, Universidad de Chile: $145 \mathrm{p}$.

Davidson, J.; Vicente, J. 1973. Características paleogeográficas y estructurales del área fronteriza de las nacientes del Teno-Chile- y Santa Elena-Argentina, Cordillera Principal, $35^{\circ}$ a $35^{\circ} 15^{\prime}$ de latitud sur. In Congreso Geológico Argentino, No. 5, Actas 5: 11-55.

Deckart, K.; Clark, A.; Aguilar, C.; Vargas, R.; Serrano, L.; Ortega, H. 2003. Geochronology of the Río Blanco porphyry $\mathrm{Cu}(-\mathrm{Mo})$ deposit, Principal Cordillera, Central
Chile (330's). In Congreso Geológico Chileno, No. 10, Actas, CD Rom, Simposio 1. Concepción.

Díaz, D. 2007. Arquitectura de la cuenca de AbanicoFarellones entre las latitudes $34-35^{\circ} \mathrm{S}$ : estudio magnetotelúrico en transectas sobre los ríos Teno y Cachapoal. Tesis de Magíster en Ciencias mención Geofísica (Inédito), Departamento de Geofísica, Universidad de Chile: $130 \mathrm{p}$.

Drake, R.; Charrier, R.; Thiele, R.; Munizaga, F.; Padilla, H.; Vergara, M. 1982. Distribución y edades K-Ar de volcanitas post-Neocomianas en la Cordillera Principal entre $32^{\circ}$ y $36^{\circ}$ L.S. Implicaciones estratigráficas y tectónicas para el Meso-Cenozoico de Chile Central. In Congreso Geológico Chileno, No. 3, Actas 1: 4278. Concepción.

Farías, M.; Comte, D.; Charrier, R. 2006. Sismicidad superficial en Chile central: Implicancias para el estado cortical y crecimiento de los Andes Centrales australes. In Congreso Geológico Chileno, No. 11, Actas 1: 403-406. Antofagasta.

Fock, A.; Charrier, R.; Farías, M.; Maksaev, V.; Fanning, M.; Álvarez, P. 2005. Deformation and uplift of the western Main Cordillera between $33^{\circ}$ and $34^{\circ} \mathrm{S}$. In International Symposium on Andean Geodynamics (ISAG), Actas, Editions IRD: 273-276. Barcelona.

Fock, A.; Charrier, R.; Maksaev, V.; Farías, M. 2006. Neogene exhumation and uplift of the Andean Main Cordillera from apatite fission tracks between $33^{\circ} 30^{\prime}$ and $34^{\circ} 00^{\prime} \mathrm{S}$. Backbone of the Americas-Patagonia to Alaska. Geological Society of America Meeting: 102. Mendoza.

Fuentes, F.; Vergara, M.; Aguirre, L.; Féraud, G. 2002. Relaciones de contacto de unidades volcánicas terciarias de los Andes de Chile central ( $\left.33^{\circ} \mathrm{S}\right)$ : una reinterpretación sobre la base de dataciones ${ }^{40} \mathrm{Ar} /{ }^{39} \mathrm{Ar}$. Revista Geológica de Chile 29 (2): 207-225.

Fuentes, F. 2004. Petrología y metamorfismo de muy bajo grado de unidades volcánicas oligoceno-miocenas en la ladera occidental de los Andes de Chile central $\left(33^{\circ} \mathrm{S}\right)$. Tesis de Doctorado (Inédito), Departamento de Geología, Universidad de Chile: 398 p.

Godoy, E. 1991. El Corrimiento del Fierro reemplaza a la discordancia intrasenoniana en el río Cachapoal, Chile central. In Congreso Geológico Chileno, No. 6, Actas: 635-639. Viña del Mar.

Godoy, E. 1998. Intrusivos sintectónicos entre los ríos Aconcagua y Cachapoal, Andes de Chile Central. In Congreso Latinoamericano de Geología, No. 10, Actas 2: 149-154. Concepción.

Godoy, E.; Lara, L. 1994. Segmentación estructural 
andina a los $33^{\circ}-34^{\circ} \mathrm{S}$ : nuevos datos en la Cordillera Principal. In Congreso Geológico Chileno, No. 7, Actas 2: 1344-1348. Concepción.

Godoy, E.; Yáñez, G.; Vera, E. 1999. Inversion of an Oligocene volcano-tectonic basin and uplifting of its superimposed miocene magmatic arc in the Chilean Central Andes: first seismic and gravity evidences. Tectonophysics 306 (3-4): 217-236.

González, O.; Vergara, M. 1962. Reconocimiento Geológico de la Cordillera de los Andes entre los paralelos $35^{\circ}$ y $38^{\circ}$ Latitud Sur. Universidad de Chile, Facultad de Ciencias Físicas y Matemáticas, Instituto de Geología, Publicaciones 24: $121 \mathrm{p}$.

Hill, D. 1977. A model for earthquake swarms. Journal of Geophysical Research 82: 1347-1352.

Hollings, P.; Cooke, D.; Clark, A. 2005. Regional Geochemistry of Tertiary igneous rocks in Central Chile: implications for the geodynamic environment of giant porphyry copper and epithermal gold mineralization. Economic Geology 100: 887-904.

Hurtado, A. 2003. Geología de la Cordillera de los Andes entre los ríos Teno y Colorado, provincia de Curicó: una contribución a la estratigrafía del Cenozoico. Memoria de Título (Inédito), Departamento de Geología, Universidad de Chile: 111 p.

Klohn, C. 1960. Geología de la Cordillera de los Andes de Chile Central. Instituto de Investigaciones Geológicas, Boletín 8: 95 p.

Kurtz, A.; Kay, S.; Tittler, A.; Mpodozis, C.; Godoy, E. 1995. Neogene magmatism in the Andean Cordillera ( $26^{\circ}$ to $34^{\circ} \mathrm{S}$ ): evidence for spatial and temporal changes in crustal thickness. EOS 76 (17): S272.

Kurtz, A.; Kay, S.; Charrier, R.; Farrar, E. 1997. Geocronology of Miocene plutons and exhumation history of the El Teniente region, Central Chile $\left(34^{\circ}-35^{\circ} \mathrm{S}\right)$. Revista Geológica de Chile 24 (1): 75-90.

Lavenu, A.; Cembrano, J. 1999. Compressional- and transpressional-stress pattern for Pliocene and Quaternary brittle deformation in fore arc and intra-arc zones (Andes of Central and Southern Chile). Journal of Structural Geology 21: 1669-1691.

Levi, B.; Aguirre, L.; Nyström, J.; Padilla, H.; Vergara, M. 1989. Low-grade regional metamorphism in the Mesozoic-Cenozoic volcanic sequences of the Central Andes. Journal of Metamorphic Petrology 7: 487-495. Maksaev, V.; Munizaga, F.; McWilliams, M.; Fanning, M.; Mathur, R.; Ruiz, J.; Zentilli, M. 2004. New chronology for El Teniente, Chilean Andes, from U/Pb, ${ }^{40} \mathrm{Ar} /{ }^{39} \mathrm{Ar}$, $\mathrm{Re} / \mathrm{Os}$ and fission-track dating: Implications for the evolution of a supergiant porphyry $\mathrm{Cu}-\mathrm{Mo}$ deposit.
In Andean Metallogeny: New discoveries, Concepts, Update. (Sillitoe, R.; Perelló, J.; Vidal, C.; editors). Society of Economic Geologists (SEG), Special Publication 11: 15-54.

Piquer, J. 2004. Ambiente geológico del Prospecto Infiernillo, cordillera de Curicó, VII Región. Memoria de Título (Inédito), Departamento de Geología, Universidad de Chile: $100 \mathrm{p}$.

Ramos, V. 1996. Evolución Tectónica de la alta cordillera de San Juan y Mendoza. In Geología de la región del Aconcagua (Ramos, V.; editor). Dirección Nacional del Servicio Geológico, Subsecretaría de Minería de la Nación, Anales 24 (16): 447-460.

Ramos, V.; Kay, S.; Pérez, D. 1996a. El volcanismo de la región del Aconcagua. In Geología de la región del Aconcagua (Ramos, V.; editor). Dirección Nacional del Servicio Geológico, Subsecretaría de Minería de la Nación, Anales 24 (10): 297-316.

Ramos, V.; Cegarra, M.; Cristallini, E. 1996b. Cenozoic tectonics of the High Andes of west-central Argentina (30-36 ${ }^{\circ} \mathrm{S}$ latitude). Tectonophysics 259: 185-200.

Serrano, L.; Vargas, R.; Stambuk, V.; Aguilar, C.; Galeb, M.; Holgrem, C.; Contreras, A.; Godoy, S.; Vela, I.; Skewes, A.; Stern, C. 1996. The Late Miocene Río Blanco-Los Bronces copper deposit, central Chilean Andes. In Andean Copper Deposits: New discoveries, Mineralization Styles and Metallogeny (Camus, F.; Sillitoe, R.; Petersen, R.; editors). Society of Economic Geologists, Special Publication 5: 119-130.

Sibson, R. 1985. A note on fault reactivation. Journal of Structural Geology 7: 751-754.

Sibson, R. 2000. A brittle failure mode plot defining conditions for high-flux flow. Economic Geology 95: 41-48.

Sibson, R. 2001. Seismogenic framework for hydrothermal transport and ore deposits. In Structural controls on ore genesis (Richards, J.; Tosdal, R.; editors). Society of Economic Geologists, Reviews in Economic Geology 14: 25-50.

Sibson, R.; Robert, F.; Poulsen, K. 1988. High-angle reverse faults, fluid-pressure cycling, and mesothermal gold-quartz deposits. Geology 16: 551-555.

Skármeta, J.; Castelli, J. 1997. Intrusión sintectónica del granito de las Torres del Paine, Andes Patagónicos de Chile. Revista Geológica de Chile 24 (1): 55-74.

Skármeta, J.; McKlay, K.; Bertens, A. 2003. Structural controls on porphyry Copper deposits in northern Chile: new models and implications for $\mathrm{Cu}-\mathrm{Mo}$ mineralization on subduction orogens. In Congreso Geológico Chileno, No. 10, Actas, CD Rom, Simposio 2. Concepción. 
Skewes, A.; Stern, C. 1995. Genesis of the Giant Late Miocene to Pliocene Copper deposits of Central Chile in the context of andean magmatic and tectonic evolution. International Geology Review 37: 893-909.

Skewes, A.; Arévalo, A.; Floody, R.; Zúñiga, P.; Stern, C. 2002. The giant El Teniente, breccia deposit: hypogene copper distribution and emplacement. In Integrated methods for discovery: Global exploration in the Twenty-first Century (Goldfarb, R.; Nielsen, R.; editors). Society of Economic Geologists, Special Publication 9: 299-332.

Spichiger, S. 1993. Geología y estilo estructural de un perfil de los Andes chilenos a $35^{\circ}$ de latitud sur, con énfasis en la Cordillera de la Costa, VII Región. Memoria de Título (Inédito), Departamento de Geología, Universidad de Chile: 112 p.

Thiele, R. 1980. Hoja Santiago, Región Metropolitana. Instituto de Investigaciones Geológicas, Carta Geológica de Chile 39: $51 \mathrm{p}$.

Tosdal, R.; Richards, J. 2001. Magmatic and structural controls on the development of porphyry $\mathrm{Cu}+\mathrm{Mo}+\mathrm{Au}$ deposits. In Structural controls on ore genesis (Ri- chards, J.; Tosdal, R.; editors). Society of Economic Geologists, Reviews in Economic Geology 14: 157-181.

Vergara, M.; Charrier, R.; Munizaga, F.; Rivano, S.; Sepúlveda, P.; Thiele, R.; Drake, R. 1988. Miocene volcanism in the central Chilean Andes. Journal of South American Earth Sciences 1 (2): 199209.

Vergara, M.; López-Escobar, L.; Palma, J.; Hickey-Vargas, R.; Roeschmann, C. 2004. Late Tertiary episodes in the area of the city of Santiago de Chile: new geochronological and geochemical data. Journal of South American Earth Sciences 17: 227-238.

Wyss, A.; Flynn, J.; Norell, M.; Swisher, C.; Novacek, M.; McKenna, M.; Charrier, R. 1994. Paleogene mammals from the Andes of Central Chile: a preliminary Taxonomic, Biostratigraphic, and Geocronologic Assessment. American Museum of Natural History 3098: $31 \mathrm{p}$.

Zapatta, F. 1995. Nuevos antecedentes estratigráficos y estructura del área de Termas del Flaco, valle del río Tinguiririca, VI Región, Chile. Memoria de Título (Inédito), Departamento de Geología, Universidad de Chile: $122 \mathrm{p}$.

Manuscrito recibido: junio 18, 2008; revisado/aceptado: junio 2, 2009. 